This item was submitted to Loughborough's Research Repository by the author.

Items in Figshare are protected by copyright, with all rights reserved, unless otherwise indicated.

\title{
A viscoplastic study of crack-tip deformation and crack growth in a nickel- based superalloy at elevated temperature
}

PLEASE CITE THE PUBLISHED VERSION

http://dx.doi.org/10.1016/j.jmps.2008.09.006

PUBLISHER

(C) Elsevier

VERSION

AM (Accepted Manuscript)

LICENCE

CC BY-NC-ND 4.0

REPOSITORY RECORD

Zhao, Liguo, and Jie Tong. 2019. "A Viscoplastic Study of Crack-tip Deformation and Crack Growth in a Nickel-based Superalloy at Elevated Temperature”. figshare. https://hdl.handle.net/2134/10909. 
This item was submitted to Loughborough's Institutional Repository (https://dspace.lboro.ac.uk/) by the author and is made available under the following Creative Commons Licence conditions.

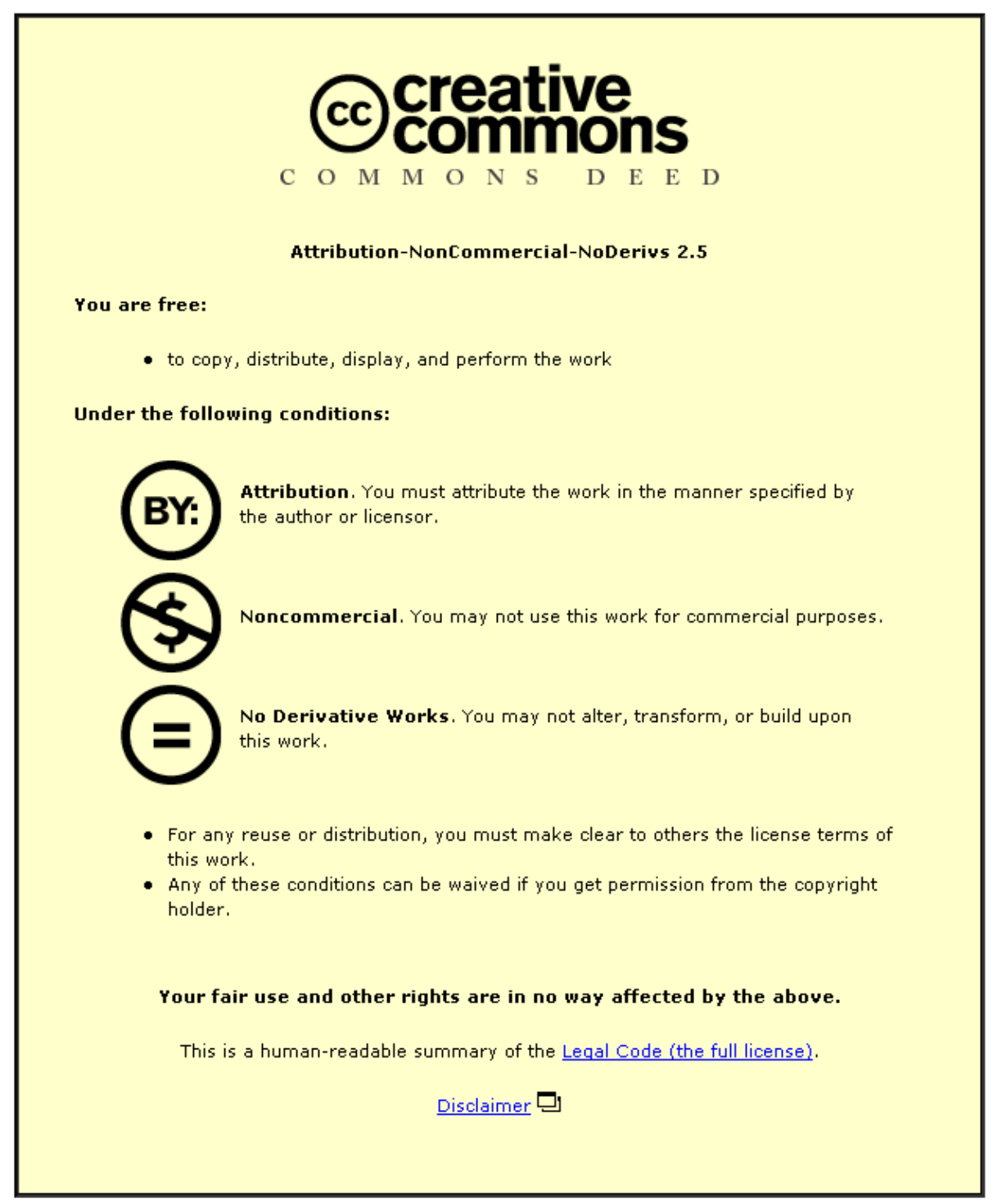

For the full text of this licence, please go to: http://creativecommons.org/licenses/by-nc-nd/2.5/ 


\title{
A Viscoplastic Study of Crack-Tip Deformation and Crack Growth in a Nickel- Based Superalloy at Elevated Temperature
}

\author{
L.G. Zhao and J. Tong \\ Department of Mechanical and Design Engineering \\ University of Portsmouth \\ Anglesea Building, Anglesea Road \\ Portsmouth, PO1 3DJ, UK
}

\begin{abstract}
Viscoplastic crack tip deformation behaviour in a nickel-based superalloy at elevated temperature has been studied for both stationary and growing cracks in a compact tension (CT) specimen using the finite element method. The material behaviour was described by a unified viscoplastic constitutive model with non-linear kinematic and isotropic hardening rules, and implemented in the finite element software ABAQUS via a userdefined material subroutine (UMAT). Finite element analyses for stationary cracks showed distinctive strain ratchetting behaviour near the crack tip at selected load ratios, leading to progressive accumulation of tensile strain normal to the crack growth plane. Results also showed that low frequencies and superimposed hold periods at peak loads significantly enhanced strain accumulation at crack tip. Finite element simulation of crack growth was carried out under a constant $\Delta K$-controlled loading condition, again ratchetting was observed ahead of the crack tip, similar to that for stationary cracks.
\end{abstract}

A crack growth criterion based on strain-accumulation is proposed where a crack is assumed to grow when the accumulated strain ahead of the crack tip reaches a critical value over a characteristic distance. The criterion has been utilised in the prediction of crack growth rates in a $\mathrm{CT}$ specimen at selected loading ranges, frequencies and dwell periods, and the predictions were compared with the experimental results.

Keywords: Viscoplastic material (B); Crack mechanics (B); Finite elements (C); Ratchetting. 


\section{Introduction}

Attempts at a mechanistic understanding of fatigue crack propagation may be traced back to Rice (1967) with his seminal analysis on the stress and strain fields near an idealized stationary crack tip under tensile and anti-plane shear cyclic loadings. It was revealed that the cyclic plastic deformation near a crack tip might be entirely determined by the variation in the stress intensity factor, and the reversed plastic zone size due to the load reversal is one quarter of the size of the maximum plastic zone. Since then, a substantial body of research work has been carried out to study the crack tip mechanics in order to shed light on the controlling parameter of crack propagation, which includes the wellknown Hutchinson-Rice-Rosengren (HRR) field for power-law hardening materials and the RR (Riedel and Rice, 1980) and the HR (Hui and Riedel, 1981) fields for power law creep materials. Crack growth simulation has also been extensively carried out to study the crack growth pattern and the crack-tip plasticity using the finite element method with cyclic plasticity and/or creep models (e.g., Sehitoglu and Sun, 1991; Pommier and Bompard, 2000; Zhao et al., 2001; Tvergaard, 2004).

Viscoplasticity or time-dependent inelastic material behaviour has been shown to play a critical role in crack tip deformation for materials subjected to cyclic loading at elevated temperature. Keck et al. (1985) demonstrated the dependency of crack tip stress-strain field and plastic-zone size on loading frequency and hold time at the maximum load, where decreased frequency and introduced hold time led to increased crack tip deformation and plastic-zone size. Finite element simulation of fatigue crack growth by Sehitoglu and Sun (1989) showed that effective stress range and crack opening level strongly depend on time-dependent constitutive relationship. Increased effective stress range and decreased crack opening level were observed when hold period was introduced at the maximum stress. Sung and Liou (1993) analytically studied the near-tip fields for transient crack growth in a viscoplastic solid under small-scale yielding conditions, where the crack tip fields were shown to depend on both time and crack propagation speed. Experimental and numerical work by Qian et al. (1996) showed marked effects of loading frequency on crack growth rate, stresses and viscoplastic strains. Anderson et al. (2001) studied fatigue crack propagation in a nickel alloy, IN718, and showed immediate crack opening upon load reversal from the minimum load, suggesting a lack of crack closure for the cases examined. 
Nickel based superalloys have been used for gas turbine discs which are subjected to variable centrifugal and thermal stresses with operation temperatures up to $700^{\circ} \mathrm{C}$. Failure of turbine discs due to the interaction of fatigue, creep and environmental effects can lead to the loss of aircraft. Alloy RR1000 is one of the latest fine-grained nickelbased superalloys, developed at Rolls-Royce plc of the UK through a powder metallurgy process, to meet the increasing demand of mechanical performance for turbine discs in the latest Trent 1000 Rolls-Royce aero engines. Fatigue and creep behaviour of Alloy RR1000 at elevated temperature have been systematically studied through crack growth testing using compact tension (CT) and corner notch (CN) specimens. Tong et al. (2001) showed that mixed time and cycle dependent crack growth seems to be the dominant crack growth mode for RR1000 at $650^{\circ} \mathrm{C}$. Knowles and Hunt (2002) investigated the influence of microstructure and environment on crack growth behaviour of RR1000 at $725^{\circ} \mathrm{C}$. Both environment and exposure-induced sigma-phase precipitation at grain boundaries were shown to increase the crack growth rate through increased crack tip cavity nucleation, whilst rapid near-tip stress relaxation induced by $\gamma^{\prime}$ coarsening has a beneficial effect on the severity of crack tip cavity damage. For short crack growth at elevated temperature, Pang and Reed (2003) showed that RR1000 demonstrated superior fatigue performance compared to Udimet 720 and was attributed to the benefit of stress relaxation due to its alloy chemistry. Most recently, Dalby and Tong (2005) systematically studied the crack growth behaviour for RR1000 at elevated temperature by considering a range of loading waveforms and frequencies. Accelerated crack growth rates were observed in specimens tested at low frequencies, long dwell periods or under slow-fast loading waveform.

Comprehensive experimental and analytical studies (Zhan and Tong, 2007a; b) have also been carried out towards a fundamental understanding of time-dependent deformation behaviour using material constitutive models. Strain-controlled cyclic tests were carried out at $650^{\circ} \mathrm{C}$ for selected strain ratio, range and rate. A unified viscoplastic model (Chaboche, 1989) was adopted and modified to describe the time-dependent constitutive behaviour of RR1000 alloy, with model parameters determined from an optimisation of the basic monotonic, cyclic and creep experimental data (Zhan and Tong, 2007a; b). 
Although viscoplastic constitutive models are available, such information has seldom been fully utilised in the studies of crack tip mechanics, where a relationship between crack tip deformation and crack growth behaviour may be obtained towards a mechanistic characterisation of crack growth, as opposed to empirical or semi-empirical models that require extensive experimental data. The main objective of this work is to study the fundamental deformation behaviour near a crack tip in alloy RR1000 at elevated temperature, using the viscoplastic constitutive model presented in Zhan and Tong $(2007 a ; b)$. Detailed finite element analyses were carried out to study the stressstrain fields near a stationary and a growing crack tip in a CT specimen under mode I cyclic loading conditions. The evolution of the stress and strain fields near a stationary crack tip was obtained and analysed, and the influence of load ratio, loading frequency and dwell period on the evolution of crack tip stress-strain field was evaluated. Fatigue crack growth was also simulated under a constant $\Delta K$-controlled condition using a node release algorithm. A damage parameter based on crack tip strain accumulation was identified from which a crack growth criterion was proposed. Using the proposed criterion, crack growth rates were predicted for selected loading ranges, frequencies and superimposed dwell times, and compared with those obtained experimentally.

\section{The Material Model}

The material model is essentially the unified constitutive equations developed by Chaboche (1989), where both isotropic $(R)$ and kinematic $(\boldsymbol{\alpha})$ hardening variables are considered during the transient and saturated stages of cyclic response. Within the smallstrain hypothesis, the strain rate tensor $\dot{\boldsymbol{\varepsilon}}$ is partitioned additively into an elastic part $\dot{\boldsymbol{\varepsilon}}_{e}$ and an inelastic part $\dot{\boldsymbol{\varepsilon}}_{p}$ :

$$
\dot{\boldsymbol{\varepsilon}}=\dot{\boldsymbol{\varepsilon}}_{e}+\dot{\boldsymbol{\varepsilon}}_{p}
$$

It is assumed that the elastic strain $\boldsymbol{\varepsilon}_{e}$ obeys the Hooke's law,

$$
\dot{\boldsymbol{\varepsilon}}_{e}=\frac{1+v}{E} \dot{\boldsymbol{\sigma}}-\frac{\boldsymbol{v}}{E}(\operatorname{tr} \dot{\boldsymbol{\sigma}}) I
$$


where $E$ and $v$ are the Young's modulus and the Poisson's ratio of the material, $\boldsymbol{\sigma}$ and $\boldsymbol{I}$ stress tensor and the unit tensor of rank two respectively, and $t r$ the trace.

The inelastic strain $\boldsymbol{\varepsilon}_{p}$ represents both plastic and creep strains. A power relationship is adopted for the viscopotential and the viscoplastic strain rate is expressed as (Chaboche, 1989):

$$
\dot{\boldsymbol{\varepsilon}}_{p}=\left\langle\frac{f}{Z}\right\rangle^{n} \frac{\partial f}{\partial \boldsymbol{\sigma}},
$$

where $f$ is the yield function, $\alpha$ is the back stress or kinematic hardening variable, $Z$ and $n$ are material constants, and the bracket is defined by

$$
\langle x\rangle=\left\{\begin{array}{l}
x, x \geq 0, \\
0, x<0 .
\end{array}\right.
$$

According to the von Mises yield criterion, the yield function $f$ is defined as

$$
f(\boldsymbol{\sigma}, \boldsymbol{\alpha}, R, k)=J(\boldsymbol{\sigma}-\boldsymbol{\alpha})-R-k \leq 0,
$$

where $R$ is the isotropic hardening variable and $k$ is the initial value of the radius of the yield surface. $J$ denotes the von Mises distance in the deviatoric stress space

$$
J(\boldsymbol{\sigma}-\boldsymbol{\alpha})=\sqrt{\frac{3}{2}\left(\boldsymbol{\sigma}^{\prime}-\boldsymbol{\alpha}^{\prime}\right):\left(\boldsymbol{\sigma}^{\prime}-\boldsymbol{\alpha}^{\prime}\right)}
$$

where $\sigma^{\prime}$ and $\alpha^{\prime}$ are the deviators of $\sigma$ and $\alpha$, represents the inner product of two tensors. Plastic flow occurs under the condition $f=0$ and $\frac{\partial f}{\partial \boldsymbol{\sigma}}: \dot{\boldsymbol{\sigma}}>0$. For this model, the motion of yield surface continues to hold but the stress in excess of the yielding stress is now admissible and often termed as "overstress". 
The evolution of the kinematic stress tensor $\alpha$ and the isotropic stress $R$ may be described through the following rules (Chaboche, 1989):

$$
\left\{\begin{array}{l}
\dot{\alpha}=\dot{\alpha}_{1}+\dot{\alpha}_{2} \\
\dot{\alpha}_{1}=C_{1}\left(a_{1} \dot{\varepsilon}_{p}-\dot{\alpha}_{1} \dot{p}\right) \\
\dot{\alpha}_{2}=C_{2}\left(a_{2} \dot{\boldsymbol{\varepsilon}}_{p}-\dot{\alpha}_{2} \dot{p}\right)
\end{array} \quad \text { and } \quad \dot{R}=b(Q-R) \dot{p}\right.
$$

where $C_{1}, a_{1}, C_{2}, a_{2}, b$ and $Q$ are six material and temperature dependent constants which determine the shape and amplitude of the stress-strain loops during the transient and saturated stage of cyclic response, and $\dot{p}$ is the accumulated inelastic strain rate defined by

$$
\dot{p}=\left\langle\frac{f}{Z}\right\rangle^{n}=\sqrt{\frac{2}{3} d \dot{\boldsymbol{\varepsilon}}_{p}: d \dot{\boldsymbol{\varepsilon}}_{p}} .
$$

The constitutive equations contain eleven material parameters, namely, $E, v, k, b, Q, C_{l}$, $a_{1}, C_{2}, a_{2}, Z$ and $n$. The kinematic hardening behaviour is described by $C_{1}, a_{1}, C_{2}$ and $a_{2}$, where $a_{1}$ and $a_{2}$ are the saturated values of the kinematic hardening variables, and $C_{1}$ and $C_{2}$ indicate the speed with which the saturation is reached. The isotropic hardening is depicted by $Q$ and $b$, where $Q$ is the asymptotic value of the isotropic variable $R$ at saturation and $b$ indicates the speed towards the saturation. The initial size of the yield surface is represented as $k, E$ is the Young's modulus, $v$ is the Poisson's ratio, $Z$ and $n$ are Iviscous parameters. The parameter values, optimized from the uniaxial test data of Alloy $\mathrm{RR} 1000$ at $650^{\circ} \mathrm{C}$, are listed in Table 1 . The above material model has been programmed into a user defined material subroutine (UMAT) using a fully implicit integration and the Euler backward iteration algorithm, and implemented in the finite element software ABAQUS (ABAQUS, 2007). Comparisons of the experimental data and the model simulations are given in Fig.1a for the first cycle of a simple strain-controlled cyclic test (strain rate $d \varepsilon / d t=0.05 \% / \mathrm{s}$ and strain range $\Delta \varepsilon=2 \%$ ), and in Fig.1b for the first cycle of a cyclic test with a 100-second hold period at both maximum and minimum strains (strain rate $d \varepsilon / d t=0.5 \% / \mathrm{s}$ and strain range $\Delta \varepsilon=2 \%$ ). It can be seen that the simulations compare very well with the experimental results. 
For the kinematic hardening rules described by equation (7), static recovery terms were excluded due to their insensitivity to stress and strain response for alloy RR1000, as shown in Zhan and Tong (2007a). In what follows, finite element analyses are presented with regard to crack tip viscoplastic deformation behaviour and associated crack growth rate for a $\mathrm{CT}$ specimen under selected loading conditions at $650^{\circ} \mathrm{C}$.

\section{Finite Element Analysis}

A standard CT specimen was considered and the finite element mesh for the specimen, shown in Fig.2, consists of four-node, first-order elements with full integration. First order elements are used here since they work better for crack growth analysis (ABAQUS, 2007). Due to symmetry, only half of the specimen was considered. The element size in the crack tip/growth area is $12.7 \mu \mathrm{m}$, about twice the average grain size $(5 \sim 6 \mu \mathrm{m})$ of the material. Cyclic load was applied to a rigid pin fitted into the hole of the specimen. The rigid pin and the hole of specimen were treated as a pair of contact surfaces (ABAQUS, 2007). For consistency, the same mesh was used to analyse the crack tip deformation for both stationary and growing cracks. For stationary crack analysis, the crack length was chosen to be $a=13 \mathrm{~mm}$, i.e., $a / W=0.5$. For growing crack analysis, a total crack growth of $1.2 \mathrm{~mm}$ was simulated, with an initial length of $12.2 \mathrm{~mm}$ and a final crack length of $13.4 \mathrm{~mm}$.

For the simulation of crack growth, it was recommended that the element size should be fine enough to capture the cyclic (reverse) plastic zone so that crack tip plasticity and associated opening level can be adequately evaluated (Sehitoglu and Sun, 1989). In the present work, for $\Delta K=20 \mathrm{MPa} \sqrt{\mathrm{m}}$ and load ratio $R=0.1$, the cyclic plastic zone is about $0.05 \mathrm{~mm}$, which would contain approximately 5 elements; while for $\Delta K=$ $40 \mathrm{MPa} \sqrt{\mathrm{m}}$ and load ratio $R=0.1$, the cyclic plastic zone is about $0.18 \mathrm{~mm}$, which would contain approximately 14 elements. The applied cyclic loading ratio $R$ was chosen to be 0.1 with a constant value of $\Delta K=40 \mathrm{MPa} \sqrt{\mathrm{m}}$, corresponding to an operational loading condition used to produce crack growth data (Dalby and Tong, 2005). For a constant value of $\Delta K$, the crack growth rate may be reasonably assumed as constant for essentially small scale yielding conditions based on the Paris law. The crack growth procedure was simulated by releasing a sequence of nodes along the path of crack growth 
at a given rate. The nodes to be released were initially bonded to a rigid surface introduced along the symmetry axis. The bonded nodes were allowed to slide along the rigid surface before the start of crack growth. A criterion of crack length versus time was used to control the crack-growth rate, i.e., the debonding of the nodes from the rigid surface. The node was released just after reaching the maximum load. As the crack grows from one nodal position to the next, the force carried by the node was gradually released to zero over a half cycle. Specifically in our work, the relative amplitude of the force carried by the node was 1.0 at the start of node debonding and reduced to 0 as a linear function of time in the followed half cycle. Contact elements were used between the crack surface and a rigid surface constructed along the symmetry axis to prevent the overlapping of crack surfaces during unloading. The default time increment (ABAQUS, 2007) was adopted, with at least 40 increments in a half cycle. The crack growth rates were simulated according to the rates obtained from the experiments (Dalby and Tong, 2005), at selected loading frequencies and dwell periods.

\section{Stationary Crack-Tip Deformation}

\subsection{Near-tip stress-strain fields}

Finite element computations were carried out over 30 cycles at selected load ratios with a maximum external load of $7 \mathrm{kN}$ and a frequency of $0.5 \mathrm{~Hz}$, conditions chosen to simulate typical operational loading conditions with growth rates lower than $5 \times 10^{-7} \mathrm{~m} /$ cycle. The normal (in the y-direction) stress-strain loops for load ratios $R=-1,0$ and 0.5 are shown in Fig.3a for a Gauss integration point just ahead of the crack tip. This integration point is located most closely to the crack tip with a polar coordinate of $\left(r=3.8 \mu \mathrm{m}, \theta \approx 45^{\circ}\right)$. The normal stress and strain in the y-direction are presented since they are perpendicular to the crack growth plane and most relevant to crack growth. For all load ratios, the stressstrain loops exhibit a progressive shift in the direction of increasing tensile strain, a phenomenon known as ratchetting or cyclic creep, where the plastic deformation during the loading portion is not balanced by an equal amount of yielding in the reverse loading direction. After 30 cycles, the accumulated normal strain reaches $2.7 \%$ for $R=0.5,3.2 \%$ for $R=0$ and $3.3 \%$ for $R=-1$. The maximum stress is relaxed towards zero mean stress, which leads to a steady-state strain ratchetting. Interestingly, the shape and area of the 
stress-strain loops at each load ratio seem to remain unchanged throughout the 30 cycles, which is also true for the stress and the strain amplitudes (see Figs 3a, 4, 5a and 6a). For load ratio $R>0$, the stress and strain amplitudes scale with the loading range $\Delta P$. Whilst for load ratio $R<0$, the stress and strain amplitudes seem to scale with the loading range $\Delta P$ at load ratio $R=0$.

The accumulation of the maximum strain is examined for selected load ratios at a constant $P_{\max }=7 \mathrm{kN}$ and the results are plotted against the number of cycles, $N$, in Fig. $3 \mathrm{~b}$. Clearly the maximum normal strain increases with the decrease of the R-ratio for a given maximum load. The accumulated maximum strains at $R=-1$ and 0 seem to be comparable and more pronounced than those at $R>0$.

The local stress ratios near the crack tip are calculated and their values at $N=30$ cycle are indicated in brackets in Fig.3b. These local stress ratios are very different from the applied load ratio $R$ due to the evolution of hysteresis inelastic deformation. Significantly lower, mostly negative, stress ratios are developed at the crack tip for applied load ratio $R$ $>0$. Slightly higher stress ratio is obtained for $R=-1$ due to the compressive stress relaxation at the minimum load level (Fig.3a). The role of local stress ratio in governing crack growth needs to be further explored, as life prediction based on crack tip deformation such as local stress/strain amplitude and ratio is more likely to be effective than that based on global loading parameters such as load range and load ratio.

The effect of varying load ratios on the crack tip deformation for a given load range was also examined. For a constant load range $\Delta P=7 \mathrm{kN}$ at $R=0.3$ and 0 , the development of the stress-strain loops at the integration point $\left(\mathrm{r}=3.8 \mu \mathrm{m}, \theta \approx 45^{\circ}\right)$ just ahead of the crack tip is shown in Fig.4. More pronounced strain accumulation occurs at $R=0.3\left(P_{\max }=10\right.$ $\mathrm{kN})$, compared with $R=0\left(P_{\max }=7 \mathrm{kN}\right)$, although, for both cases, the stress and strain ranges remain almost constant and scale with the applied load range for each successive cycle.

The continuous increase of tensile strain may be of particular significance for crack growth as it will eventually lead to material separation near the crack tip. In fact, Kapoor (1994) defined two modes of failure in ductile rupture: low cycle fatigue and ratchetting. 
If a strain cycle is closed the failure takes place mainly by low cycle fatigue, while if a strain cycle is open, ratchetting will occur and the accumulated tensile strain may lead to final failure. Ratchetting has been increasingly recognised as a fatigue failure mechanism for metallic materials and alloys under asymmetric cyclic stressing (Kapoor, 1994; Yaguchi and Takahashi, 2005; Kang et al., 2006). In the near-tip stress-strain field, the accumulated tensile strain increases with the increase of maximum load (for a constant load range) and the decrease of load ratio (for a constant maximum load). These cases $\left(\mathrm{d} a / \mathrm{d} N<5.0 \times 10^{-7} \mathrm{~m} /\right.$ cycle $)$ may be relevant to slow crack growth near fatigue thresholds. For example, for a given maximum load, more pronounced tensile strain is accumulated at lower R-ratios (Fig.3b), hence low fatigue thresholds are usually obtained at low R-ratios; while for a constant load range, the fatigue thresholds are lower at high R-ratios, due to the more significant accumulation of tensile strain (Fig. 4).

Experimental results showed that, for strain-controlled tests at $650^{\circ} \mathrm{C}$, no more than 30 cycles are normally required to reach cyclic saturation for alloy RR1000 (Zhan and Tong, 2007a), which is the number of cycles used in the above analysis. Numerically, although ratchetting near the crack tip remains after 30 cycles, ratchetting rate seems decreasing with increasing number of cycles and approaching a steady state. Further analyses up to 400 cycles also confirmed that crack tip ratchetting continues with the number of cycles, but at a decreasing rate, arriving at a steady state rather than stop completely. Nevertheless, the exact number of cycles used for analysis is only meaningful when crack growth rates are above the fatigue threshold of $10^{-7} \sim 10^{-8} \mathrm{~m} /$ cycle (ASTM standards). As mentioned above, the stationary crack analyses reveal crack tip deformation for slow crack growth (at a rate lower than $5 \times 10^{-7} \mathrm{~m} /$ cycle), and the chosen cycle number 30 would give a slow growth rate of $4.2 \times 10^{-7} \mathrm{~m} /$ cycle (considering the mesh size of 12.7 um near crack tip), which is above the fatigue threshold.

\subsection{Effect of frequency on crack tip deformation}

Crack growth rates at elevated temperature in nickel alloys are sensitive to loading frequency (Dalby and Tong, 2005), an attribute of time-dependent material behaviour. To gain a mechanistic understanding of the phenomenon, analyses were performed to examine the response of crack tip deformation to selected loading frequencies using the 
unified viscoplastic constitutive model. Triangular loading waveforms were considered, with selected frequencies between $0.005 \mathrm{~Hz}$ and $0.5 \mathrm{~Hz}$. The obtained stress-strain loops are shown in Fig.5a for an integration point $\left(\mathrm{r}=3.8 \mu \mathrm{m}, \theta \approx 45^{\circ}\right)$ located just ahead of the crack tip. The developed strain accumulation due to ratchetting increases with the decrease of loading frequency, consistent with the enhanced viscoplastic deformation due to reduced loading rate.

The accumulated strain is shown in Fig.5b against the number of cycles for selected loading frequencies. It seems clear that the lower the frequency, the higher the accumulated strain. Assuming strain accumulation as the predominant failure mode, it is plausible that crack will grow faster under loading conditions at lower frequencies. This is consistent with the experimental results, where faster crack growth rates were obtained at lower frequencies (Dalby and Tong, 2005).

\subsection{Effect of dwell on crack tip deformation}

It is well known that the introduction of a hold period in cyclic loading (dwell) has a detrimental effect on the low cycle fatigue life in Alloy RR1000 at elevated temperature (Dalby and Tong, 2005). The fatigue life may be reduced by about a third with a 100second dwell period introduced at the maximum load at $650^{\circ} \mathrm{C}$ (Dalby and Tong, 2005). To study the effect of dwell on crack tip deformation behaviour, hold periods between 10 seconds and 1000 seconds were added at the maximum load for a load ratio of $R=0$ and a baseline frequency of $f=0.5 \mathrm{~Hz}$. The stress-strain loops for the $1^{\text {st }}, 10^{\text {th }}$ and $30^{\text {th }}$ cycles are plotted in Fig.6a for the integration point $\left(r=3.8 \mu \mathrm{m}, \theta \approx 45^{\circ}\right)$ just ahead of the crack tip, together with those without dwell. After 30 cycles, strain accumulation is significantly increased by the addition of a dwell period, as a result of enhanced viscoplastic deformation at the peak load.

A plot of the maximum normal strain against the number of cycles is shown in Fig.6b for selected dwell periods. A marked increase of accumulated strain was displayed as soon as a 10-second dwell period was applied, and an increase in dwell duration also increased the strain accumulation. The amount of increase in strain accumulation does not seem to be proportional to the hold duration and tends to attenuate with further increase of the 
hold duration beyond 100 seconds. Again, the enhanced strain accumulation due to dwell may be used to explain the faster fatigue crack rates observed in the experiments, as reported in Dalby and Tong (2005).

Material deformation behaviour may be classified as strain controlled (constant strain rate) or stress controlled (constant stress rate). For viscoplastic materials, deformation characteristics associated with stress or strain controlled tests may include stress relaxation for strain-controlled dwell tests and creep for stress-controlled dwell tests. The predominant loading mode at the crack tip may be of fundamental importance in the characterisation of crack growth. The stress and strain rates near the crack tip were examined for a remote monotonically load-controlled test and presented in Fig.7a and Fig.7b. The strain rate seems to remain fairly constant, whilst the stress rate varies significantly for majority of the loading period, indicating the dominance of straincontrolled deformation under monotonic loading conditions. Further, the stress and strain evolutions at the crack tip during a 100-second hold periods were examined. Figure $7 \mathrm{c}$ shows stress relaxation during the hold periods at the maximum load, similar to that for a strain-controlled test. On the other hand, Figure $7 \mathrm{~d}$ shows an increase in the strain level during the dwell periods, similar to that for a stress-controlled test, albeit to somewhat a lesser extent. It is conceivable that crack tip deformation is predominantly under staincontrol for monotonic loading, while a combination of stress- and strain-controlled deformation behaviour occurs for dwell loading conditions.

\section{Simulation of Fatigue Crack Growth}

To simulate a growing crack, a constant $\Delta K$-controlled loading condition was applied, where a constant crack growth rate was assumed (Dalby and Tong, 2005). Details of the simulation procedure may be referred to Section 3. During the simulation, the stressstrain behaviour for a growing crack was studied by monitoring a particular element located on the crack growth path ahead of the crack tip. In this work, the distance of the monitored element from the original crack tip, defined as $l_{0}$, needs to be at least $0.1 \mathrm{~mm}$ (> 8 elements) in order to allow crack growth to reach a steady state, i.e., the crack tip grows out of the influence of the inelastic deformation of initial monotonic loading. Simulations of crack growth were performed by considering selected loading frequencies 
and dwell periods, for which different crack growth rates are assigned according to the experimental results (Dalby and Tong, 2005).

\subsection{Stress-strain behaviour}

To study the stress-strain behaviour for a growing crack, a crack growth rate of $6.35 \times 10^{-6}$ $\mathrm{m} /$ cycle was chosen in the first instance, where the crack grows over one element in every two cycles. The applied triangular-waveform load has a constant value of $\Delta K=$ $40 \mathrm{MPa} \sqrt{\mathrm{m}}$ with load ratio $R=0.1$ and loading frequency $f=0.5 \mathrm{~Hz}$. Evolution of stress and strain was studied by monitoring an element located along the crack growth path and $0.3 \mathrm{~mm}$ ahead of the original crack tip $\left(l_{0}=0.3 \mathrm{~mm}\right)$. For the simulated crack growth rate, it took 50 cycles for the crack tip to grow into and pass over the monitored element. The obtained stress-strain loops for the first integration point of the monitored element are shown in Fig.8a, with an inserted illustration of the positions of the monitored element and the integration point. Stresses and strains gradually increase as the distance between the monitored element and the crack tip reduces. Significantly increased levels of stress and strain were developed as soon as the crack grew close to the monitored position, due to severe deformation in the vicinity of crack tip. The stresses experienced a dramatic drop soon after the crack tip passed over the monitored element, reflecting the stress-free nature of fractured crack surface. Again, the distinctive feature of ratchetting strain accumulation may be clearly observed from the stress-strain loops, similar to that found for stationary cracks (Section 4). The final accumulated strain for the monitored integration point was about $3 \%, 2 / 3$ of which was from the deformation accumulated in the last two cycles before the crack grows beyond the monitored element. This suggests that crack tip inelastic deformation is highly localised and it may well control the material separation near the crack tip hence prompt crack growth.

The evolution of stress and strain ratios for the monitored element is shown in Fig. $8 \mathrm{~b}$ as a function of the number of cycles. At the early stage, the monitored integration point was far ahead of the crack tip and the stress behaved essentially elastic, with stress ratios about the same as the remote loading ratio 0.1 . As soon as the crack grew near the monitored element, negative ratios started to develop as a result of compressive stress developed during unloading. As the crack tip grew into the element, the local stress ratio 
was about -0.57 , as opposed to the applied load ratio 0.1 . This observation is similar to that found in stationary crack situation. On the other hand, strain ratios remained positive, albeit with values somewhat different from the remote nominal load ratio when near the crack tip.

\subsection{Effects of frequency and dwell}

To study the effects of frequency on crack tip deformation of a growing crack, two cases representing relatively low $(0.001 \mathrm{~Hz})$ and high $(0.25 \mathrm{~Hz})$ frequencies were considered for a triangular loading waveform. The crack growth rate was chosen to be $3.175 \times 10^{-6}$ $\mathrm{m} /$ cycle for $0.25 \mathrm{~Hz}$ and $1.27 \times 10^{-6} \mathrm{~m} /$ cycle for $0.001 \mathrm{~Hz}$, according to the experiments (Dalby and Tong, 2005). Numerically, these growth rates were achieved by growing the crack over one element in ten cycles for $0.25 \mathrm{~Hz}$ and in four cycles for $0.001 \mathrm{~Hz}$. The obtained stress-strain loops for an element located at $l_{0}=0.1 \mathrm{~mm}$ ahead of the original crack tip are shown in Fig.9a. The loops are similar to those presented in Fig.8a, except that crack tip undergoes more loading cycles before its growth. As seen in Fig.9a, for both frequencies, strain accumulation occurs over the applied loading cycles due to ratchetting. At the crack tip, strain accumulation rate is $0.152 \%$ per cycle at $0.001 \mathrm{~Hz}$ and $0.096 \%$ per cycle at $0.25 \mathrm{~Hz}$, indicating higher strain accumulation rate at a lower frequency. Accumulated strain was also calculated for four cycles after the crack tip grows into the monitored element, with a value of $3.1 \%$ at $0.001 \mathrm{~Hz}$ and $2.7 \%$ at $0.25 \mathrm{~Hz}$, as shown in Fig.9a. A comparison of the accumulated strain against the number of cycles is shown in Fig.9b, the total accumulated strain for crack growth over a distance $l_{0}$ (i.e., until the crack tip passed over the monitored element) seems to be comparable, i.e., $-3.3 \%$ for $f=0.25 \mathrm{~Hz}$ and $\sim 3.1 \%$ for $f=0.001 \mathrm{~Hz}$. Due to the faster strain accumulation rate at $f=0.001 \mathrm{~Hz}$, only 32 cycles are required to reach this strain level, as opposed to 80 cycles required at $f=0.25 \mathrm{~Hz}$.

The effects of dwell on crack tip deformation of a growing crack were also studied by introducing a hold period of 10 and 100 seconds at the maximum load in a trapezoidal loading waveform with a baseline frequency of $0.25 \mathrm{~Hz}$. The simulated crack growth rates are $3.175 \times 10^{-6} \mathrm{~m} /$ cycle for 100 -second dwell and $1.27 \times 10^{-6} \mathrm{~m} /$ cycle for 10 -second dwell according to the experimental results of Dalby and Tong (2005). To achieve this 
crack growth rate numerically, the crack was made to grow over one element in ten cycles for 10-second dwell and in four cycles for 100-second dwell. The obtained stressstrain loops for an element located at $0.1 \mathrm{~mm}$ ahead of the original crack tip are shown in Fig.10a, where strain is shown to accumulate over the applied loading cycles due to ratchetting. On the other hand, stress relaxation during the hold period can be clearly seen from the stress-strain loops, which is similar to Fig.7a and b for stationary crack situation. The comparison of strain accumulation is shown in Fig.10b against the number of cycles for both cases, where the total accumulated strain for crack growth over a distance $l_{0}$ (i.e., until the crack tip passed over the monitored element) seems comparable, i.e., $3.1 \%$ for 100 second dwell and $3.5 \% \mathrm{~Hz}$ for 10 second dwell. For crack tip deformation, the average strain accumulation rate is $0.102 \%$ per cycle for 100 -second dwell and $0.063 \%$ per cycle for 10 -second dwell, indicating more strain accumulation for longer dwell period. Strain accumulation reaches a value of $3.1 \%$ for 100 second dwell and $2.7 \%$ for 10 second dwell in four cycles after the crack tip grows into the monitored element, as shown in Fig.10a. Due to the higher strain accumulation rate for 100s dwell, fewer cycles are required to reach a given level of accumulated strain compared to $10 \mathrm{~s}$ dwell.

Similar to stationary crack analysis, crack tip deformation for a growing crack also shows the distinctive feature of strain accumulation. The strain accumulation rate seems to depend on the loading frequency and dwell period. Lower frequency and longer dwell period enhance strain ratchetting and strain accumulation. This is consistent with the observed dependency of crack growth rate on frequency and dwell period from the experimental results (Dalby and Tong, 2005), i.e., faster crack growth rate at lower frequency and longer dwell period.

Rachetting-induced strain accumulation seems to be the most significant event ahead of the crack tip, and it is plausible that progressive accumulation of inelastic deformation may lead to eventual material separation. As evidenced by a large body of experimental work, ratchetting has major implications on material damage and fatigue life in service loading conditions (e.g., Kapoor, 1994; Yaguchi and Takahashi, 2005; Kang et al., 2006). One frequently cited example is rolling contact fatigue (Kapoor and Johnson, 1994), where a combination of high normal and shear tractions is imposed on a thin layer of 
material near the contact surface and leads to accumulation of shear strain in the material. As proposed by Kapoor (1994), ratchetting failure will take place when the total accumulated strain reaches a critical value. This failure criterion has been successfully utilised to rationalise and predict failure of a range of metallic materials (Kapoor, 1994), and also incorporated in design criteria for 316FR stainless steel in fast breeder reactor plant application (Date et al., 2007). The extensive FE analyses presented above reveal the distinctive racthetting feature at crack tip for a range of loading conditions, which seems to suggest that strain accumulation may be used as a damage parameter to predict crack growth rate at elevated temperature.

\section{Predictions of Crack Growth Rate}

Using the crack propagation criterion described above, crack growth rates in CT specimens at $650^{\circ} \mathrm{C}$ were predicted from the finite element analyses of crack tip deformation for selected loading conditions. During the analyses, the number of cycles was recorded when the strain accumulation over the characteristic distance $d^{*}=12.7 \mu \mathrm{m}$ ahead of the crack tip reached a critical value of $4.7 \%$. This critical strain value was back calculated using finite element analysis, which predicts the same crack growth rate $\left(1.188 \times 10^{-6} \mathrm{~m} /\right.$ cycle $)$ as the experimental result in Dalby and Tong (2005) for a base-line fatigue test $(\Delta K=40 \mathrm{MPa} \sqrt{\mathrm{m}}, f=0.25 \mathrm{~Hz}$ and $R=0.1)$ at $650^{\circ} \mathrm{C}$. The average crack growth rate was then calculated by dividing the characteristic distance with the recorded number of cycles.

Figure 11 shows the predicted crack growth rates against $\Delta K$ for a triangular waveform with frequency $f=0.25 \mathrm{~Hz}$ and load ratio $R=0.1$. Experimental data, obtained from standard fatigue testing of CT specimens under the same loading conditions (Dalby and Tong, 2005), are also included for a comparison. In addition, predicted crack growth rates at room temperature are also presented in Fig.11, with a comparison to experimental results (Dalby, 2002). In this case, a time-independent material constitutive model presented in Zhao et al. (2004) was used for the finite element analysis. From finite element analysis of crack tip deformation under triangular waveform load with $\Delta K=$ $40 \mathrm{MPa} \sqrt{\mathrm{m}}, f=0.25 \mathrm{~Hz}$ and $R=0.1$, the critical strain value for room temperature was found to be $6.7 \%$ which gives the same growth rate $\left(4.885 \times 10^{-7} \mathrm{~m} /\right.$ cycle $)$ as the 
experimental result in Dalby (2002) for the same loading conditions, hence predictions were made using this critical strain as a reference strain. From Fig.11, it can be seen that the predictions are reasonably close to the test data, and also, as expected, predicted crack growth rates at $650^{\circ} \mathrm{C}$ are faster than those at room temperature due to viscoplastic deformation at elevated temperature.

The predicted effects of loading frequency on crack growth rates are shown in Fig.12 for a triangular waveform with $\Delta K=40 \mathrm{MPa} \sqrt{\mathrm{m}}$ and load ratio $R=0.1$, including the test data for $\mathrm{CT}$ specimens at $650^{\circ} \mathrm{C}$. The predictions showed the same trend as the experimental data, i.e., the increase of crack growth rate with the decrease of loading frequency, due to the enhanced crack tip deformation for lower frequencies. The predictions agree well with the test data for higher frequency region $(f>0.1 \mathrm{~Hz})$, while marked difference is noted in the lower frequency region $(f<0.01 \mathrm{~Hz})$. This difference may be due to the oxidation effect at high temperature, which was not taken into account in the current model prediction.

The effects of dwell period on crack growth rates are predicted by considering a trapezoidal loading waveform with $\Delta K=40 \mathrm{MPa} \sqrt{\mathrm{m}}$, baseline frequency $f=0.25$ and load ratio $R=0.1$. The predictions are presented in Fig.13, including the experimental data for $\mathrm{CT}$ specimens at $650^{\circ} \mathrm{C}$ under the same loading conditions. Again the predictions show the same trend as the experimental data, i.e., the increase of crack growth rate with the increase of hold period. On the other hand, the predictions show an increasing difference between the prediction and the experimental data as the dwell period is increased, especially when the dwell period is over 100 seconds. Again, this difference may be due to the oxidation effect at high temperature, which is not accounted for in the current model prediction.

The detrimental effects of environmental factors, in particular oxygen, on hightemperature crack growth behaviour in nickel alloys have been well demonstrated by experimental results (e.g., Ghonem and Zheng, 1992; Molins et al., 1997). For RR1000 alloy, environmental effects were observed to modify the fracture morphology from transgranular to predominantly intergranular during fatigue crack growth, as well as to increase the growth rates significantly at a given stress intensity (Tong et al., 2001; 
Knowles and Hunt, 2002; Tong et al., 2005). The effect of oxidation on crack growth is more pronounced at low frequencies and long dwell periods. Oxidation-accelerated crack growth is a direct consequence of oxygen diffusion into the material, which attacks the grain boundary through chemical reaction with alloy elements or oxygen segregation at grain boundaries. The diffusion process becomes more significant with the assistance of high tensile stress near crack tip (Calvarin-Amiri et al., 2001), especially for superimposed dwell periods at the maximum load where the crack tip is fully open and experiences the highest tensile stress level. As a consequence, a coupled mechanicaldiffusion analysis (Carranza and Haber, 1999) at microstructure level may be desirable to account for the effects of oxygen diffusion as well as that of viscoplasticity on crack growth.

\section{Discussion}

Continuum mechanics treatment of fatigue crack growth places much significance on the variation of elastic stress intensity factor, which is generally believed to control the plastic deformation under small scale yielding conditions (Rice, 1967). This consensus has been reached largely based on the successful correlation of crack growth rates in terms of stress intensity factor range for a range of materials. Dimensional considerations suggested that relevant variables for a crack of length $a$ in a large body are:

$\Delta \sigma, a, \sigma_{0}, \varepsilon_{0}, \varepsilon_{\mathrm{f}}, N^{\prime}, \mathrm{d} a / \mathrm{d} N$,

where $\sigma_{0}$ and $\varepsilon_{0}$ are the yield stress and strain, $N^{\prime}$ is the hardening exponent or some other dimensionless variables characterizing the hardening behaviour, and $\varepsilon_{\mathrm{f}}$ is a characteristic fracture strain. Whilst the applied stress and instantaneous crack length are usually considered in the form of stress intensity factor range, the role of a characteristic fracture strain has not been well explored. Significant work in this direction includes McClintock (1963; 1965) who developed a mechanistic analysis of crack extension by fatigue, employing an anti-plane shear perfect plasticity solution and a failure criterion based on plastic strain accumulation over a "structural size" of the material. Quantitatively, a structural size of $5 \mu \mathrm{m}$ seems to fit well with the experimental results for three types of materials (McClintock and Irwin, 1965). McClintock's studies provided the framework 
for tensile crack growth in ductile materials, particularly with regard to micromechanisms involved in material separation. Krafft (1964) proposed that ductile fracture would occur when the instability strain for a uniaxial tensile specimen is achieved at the crack tip over a distance equal to the spacing of void nucleating particles. Ritchie et al. (1973) successfully predicted fracture when the critical stress was achieved over two grain sizes. Rawal and Gurland (1977) reported a critical stress was achieved over a critical distance about 1.3 grain-sizes. Chen et al. (2003) reported a characteristic distance of $13 \mu \mathrm{m}$ for crack tip fracture in a C-Mn steel, over which the critical strain, the critical stress and the critical stress triaxiality criteria are satisfied simultaneously. Said and Tasgetiren (2004) used the characteristic distance of 0.8 1.37 grain size to determine the static and dynamic fracture toughness for bcc metals and alloys using the critical stress criterion. In the present work, the chosen distance $d^{*}$ is on the same order as some of the published work (Krafft, 1964; McClintock and Irwin, 1965; Ritchie et al., 1973; Rawal and Gurland, 1977; Chen et al., 2003; Said and Tasgetiren, 2004). At about twice the average grain size, this characteristic distance $d^{*}$ may be associated with the cracking of a couple of grains. For convenience, the distance $d^{*}$ also corresponds to the dimension of one element $(12.7 \mu \mathrm{m})$ ahead of the crack tip in the finite element mesh. Mesh sensitivity study showed that the strain distribution ahead of the crack tip has reached a good convergence at $d^{*}=12.7 \mathrm{um}$ for the mesh used in the present work (within 5\% difference between the present mesh and a doubly refined mesh).

The choice of characteristic distance introduces a physical length scale, associated with the fracture process, hence avoiding issues associated with the stress and strain singularity ahead of a sharp crack tip. Under triangular loading waveform with $\Delta K=$ $40 \mathrm{MPa} \sqrt{\mathrm{m}}, f=0.25 \mathrm{~Hz}$ and $R=0.1$ at $650^{\circ} \mathrm{C}$, finite element analysis showed that the accumulated strain would reach a level of $4.7 \%$ over $d^{*}=12.7 \mu \mathrm{m}$ for a growth rate of $1.188 \times 10^{-6} \mathrm{~m} / \mathrm{cycle}$, as experimentally reported in Dalby and Tong (2005) for the same loading conditions. The value of $4.7 \%$ was used as the critical strain value for the prediction of crack growth prediction at $650^{\circ} \mathrm{C}$ (Figs 11-13), which is also close to the failure strain for uniaxial ratchetting tests of RR1000 smooth specimens at $650^{\circ} \mathrm{C}$ (Cornet et al., 2008). 
Crack growth criterion proposed in the current work is essentially a strain-based approach, which has been widely used for the prediction of viscoplastic failures such as creep (e.g., Riedel and Rice, 1980; Yatomi, 2003; Zhao et al., 2006). The strains local to a crack tip are of multiaxial nature such that an equivalent strain, which accounts for all strain components, is often adopted as a damage parameter (e.g., Riedel and Rice, 1980; Ritchie and Thompson, 1985; Yatomi, 2003; Zhao et al., 2006). In the current work, however, only the strain component normal to the crack growth plane was considered, as it is most relevant to material separation in mode I, and it also coincides with the maximum principal strain (Qian et al., 1996). As proposed by Kapoor (1994), two modes of failure may be identified in ductile fatigue rupture: low cycle fatigue (LCF) and ratchetting. According to Kapoor (1994), if a strain cycle is closed, then failure takes place by LCF; while if a strain cycle is open, tensile strain will develop and failure by ratchetting will occur. Ratchetting failure occurs when the accumulated strain reaches a critical value $\varepsilon_{\mathfrak{c}}$, which may be comparable with the strain to failure in a monotonic test. LCF and ratchetting failure are competitive independent failure mechanisms, and whichever corresponds to an earlier failure governs the life of the specimen (Kapoor, 1994). Our results showed that the local stress and strain amplitudes neat the crack tip scales with the applied load range and their variation with the number of cycle is negligible (e.g., Figs $3 \mathrm{a}$ and $8 \mathrm{a}$ ). On the other hand, progressive increase in strain accumulation with the number of cycles seems to suggest unambiguously ratchetting as the dominant crack driving force for crack growth. In the present work, the value of the critical strain for Alloy RR1000 was back calculated using finite element analysis, which predicts the same crack growth rate as the experimental result in Dalby (2002) and Dalby and Tong (2005) for a base-line fatigue test $(\Delta K=40 \mathrm{MPa} \sqrt{\mathrm{m}}, f=0.25 \mathrm{~Hz}$ and $R=0.1)$. The obtained value is $6.7 \%$ for room temperature and $4.7 \%$ for $650{ }^{\circ} \mathrm{C}$, indicating a dependency of the critical strain value on temperature. The strain-based crack growth criterion is according to the evolution of the stress-strain loops at the crack tip, hence is more relevant to crack tip mechanics and physical process of material separation. The fact that this criterion predicts reasonably well the effect of frequency and dwell time on crack growth rate is also encouraging. Although ratchetting has been used as a failure criterion in wear-related studies (Kapoor, 1997), the present work is the first time that such a concept is introduced in crack growth characterisation. 
Stress-controlled rachetting tests have recently been carried out on cylindrical smooth specimens for alloy RR1000 at $650^{\circ} \mathrm{C}$, together with model predictions (Cornet et al., 2008). The model prediction utilising parameters obtained from strain-controlled test data overestimated ratchetting when compared with the experimental results. The model parameters were re-estimated by considering stress-controlled as well as strain-controlled test data in Cornet et al. (2008), with significantly improved prediction of ratchetting. The new set of parameters was then used to predict the crack tip deformation again. A similar pattern of ratchetting at the crack tip was observed, showing little influence of material parameters on strain accumulation behaviour at crack tip (Cornet et al., 2008). This may be due to the fact that crack tip deformation is a mixture of strain-controlled and stress-controlled deformation. In cases where strain-control is dominant (see Figs 7a and $b$ ), the inaccuracy of prediction of stress-controlled ratchetting becomes less relevant (Cornet et al., 2008).

Although the deformation behaviour of the compact tension specimen near the crack tip seems to be more of strain-controlled than of stress-controlled (Figs 7a and b), a mixture of both (Figs 7c and d) may be more likely (Wilson and Palazotto, 1986), which would call for a mixed criterion, i.e., a combination of ratchetting and range-based LCF failure criteria (McMeeking, 1977; Kapoor, 1994). Nevertheless, it is plausible that the local stress/strain amplitudes are related to strain ratchetting, as larger strain and stress amplitudes tend to produce more pronounced strain ratchetting due to more extensive inelastic deformation (Cornet et al., 2008). Hence although the proposed criterion does not contain explicitly the terms of stress and strain amplitudes, these parameters may be implicitly accounted for in a criterion based on critical strain accumulation. The proposed criterion remains a hypothesis as detailed experimental validation is not possible currently, due to the limited resolution of measurement tools near the crack tip. Nevertheless, this simple criterion, with its clear physical meaning, may be useful before more sophisticated physically based alternatives become available.

\section{Conclusions}

Viscoplastic finite element simulations of a stationary and an advancing crack under cyclic loading have been carried out in a CT specimen using a unified constitutive model. 
Distinctive ratchetting behaviour has been observed near the crack tip for both stationary and growing cracks. The ratchetting behaviour largely depends on the loading range, ratio, frequency and dwell period.

Fatigue crack growth at elevated temperature seems to be strongly related to ratchettinginduced strain accumulation near the crack tip. It is hypothesised that crack growth occurs when the accumulated strain ahead of the crack tip reaches a critical value over a characteristic distance. This new crack growth criterion was reasonably successful in predicting the crack growth rate at selected loading range, frequency and dwell period, although for crack growth at lower frequencies and longer dwell periods, oxidation gains significance which should be taken into account in future model development.

\section{Acknowledgements}

This work was carried out in collaboration with the Rolls-Royce plc of the UK.

\section{References}

ABAQUS, 2007. Version 6.6, Hibbitt, Karlsson \& Sorensen, Inc.

Andersson, H., Persson, C., Hansson, T., 2001. Crack growth in IN718 at high temperature. International Journal of Fatigue 23, 817-827.

Calvarin-Amiri, G., Huntz, A.M., Molins, R., 2001. Effect of an applied stress on the growth kinetics of oxide scales formed on $\mathrm{Ni}-20 \mathrm{Cr}$ alloys. Materials at High Temperatures 18, 91-99.

Carranza, F.L., Haber, R.B., 1999. A numerical study of intergranular fracture and oxygen embrittlement in an elastic-viscoplastic solid. Journal of the Mechanics and Physics of Solids 47, 27-58.

Chaboche, J.L., 1989. Constitutive equations for cyclic plasticity and cyclic viscoplasticity. International Journal of Plasticity 5, 247-302.

Chen, J.H., Wang, Q., Wang, G.Z. and Li, Z., 2003. Fracture behaviour at crack tip - a new framework for cleavage mechanism of steel, Acta Materialia, 51, 1841-1855.

Cornet, C., Zhao, L.G., Tong, J., 2008. Ratchetting as a controlling mechanism for crack growth at elevated temperature, in preparation. 
Dalby, S., 2002. The effects of frequency and waveshape on the fatigue crack growth of an advanced nickel base superalloy at elevated temperatures. Ph.D thesis, University of Portsmouth.

Dalby, S., Tong, J., 2005. Crack growth in a new nickel-based superalloy at elevated temperature, part I: effects of loading waveform and frequency on crack growth. Journal of Materials Science 40, 1217-1228.

Date, S., Ishikawa, H., Otani, T., Takahashi, Y., 2007. Effect of ratchetting deformation on fatigue and creep-fatigue life of 316FR stainless steel. Nuclear Engineering and Design, in press.

Floreen S. and Kane H., 1976. A critical strain model for the creep fracture of nickel-base superalloys, Metallurgical Transactions A, 7A, 1157-60.

Ghonem, H, Zheng, D., 1992. Depth of intergranular oxygen diffusion during environment-dependent fatigue crack growth in alloy 718. Materials Science and Engineering A150, 151-160.

Hui, C.Y., Riedel, H., 1981. The asymptotic stress and strain field near the tip of a growing crack under creep conditions. International Journal of Fracture 17, 409-425.

Kang, G., Liu, Y., Li, Z., 2006. Experimental study on ratchetting-fatigue interaction of ss304 stainless steel in uniaxial cyclic stressing. Materials Science and Engineering A, 435-436, 396-404.

Kapoor, A., 1994. A re-evaluation of the life to rupture of ductile metals by cyclic plastic strain. Fatigue and Fracture of Engineering Materials and Structures 17, 201-219.

Kapoor, A., Johnson, K.L., 1994. Plastic ratchetting as a mechanism of metallic wear. Proc. R. Soc. Lond. A 445, 367-381.

Keck, J.E., Nicholas, T., Palazotto, A.N., 1985. High temperature viscoplastic fatigue behaviour of a compact tension specimen. Engineering Fracture Mechanics 22, 7791.

Knowles, D.M., Hunt, D.W., 2002. The influence of microstructure and environment on crack growth behaviour of powder metallurgy nickel superalloy RR1000. Metallurgical and Materials Transactions A 33, 3165-3172.

Krafft, J.M., 1964. Crack toughness and strain hardening of steels. Applied Materials Research 3, 88-101.

McClintock, F.A., 1963. On the plasticity of the growth of fatigue cracks, in Fracture of Solids, John Wiley \& Sons Inc., New York. 
McClintock, F.A., Irwin, G.R., 1965. Plasticity aspects of fracture mechanics. Fracture Toughness Testing and Its Applications, ASTM STP 381, pp.84-113.

McMeeking, R.M., Finite deformation analysis of crack-tip opening in elastic-plastic materials and implications for fracture. Journal of the Mechanics and Physics of Solids 25, 357-381.

Molins, R., Hochestetter, G., Chassaigne, J.C., Andrieu, E., 1997. Oxidation effects on the fatigue crack growth of alloy 718 at high temperature. Acta Materialia 45, 663674.

Pang, H.T., Reed, P.A.S., 2003. Fatigue crack initiation and short crack growth in nickelbase turbine disc alloys - the effects of microstructure and operating parameters. International Journal of Fatigue, 25, 1089-1099.

Pommier, S., Bompard, P., 2000. Bauschinger effect of alloys and plasticity-induced crack closure: A finite element analysis. Fatigue and Fracture of Engineering Materials and Structures 23, 129-139.

Qian, Z., Takezono, S., Tao, K., 1996. Effect of loading frequency on fatigue crack growth under high temperature. International Journal of Solids and Structures 33, 3601-3610.

Rawal, S.P., Gurland, J., 1977. Observations on the effect of cementite particles on the fracture toughness of spheroidized carbon steels. Metallurgical Transactions A 8, 691-698.

Rice, J.R., 1967. Mechanics of crack tip deformation and extension by fatigue. In: Fatigue Crack Propagation, ASTM STP 415, pp. 247-309.

Riedel, H., Rice, J.R., 1980. Tensile cracks in creeping solids. ASTM STP 700, 112-130.

Ritchie, R.O., Knott, J.F., Rice, J.R., 1973. On the relationship between critical tensile stress and fracture toughness in mild steel. Journal of the Mechanics and Physics of Solids 21, 395-410.

Ritchie, R.O., Thompson, A.W., 1985. On macroscopic and microscopic analyses for crack initiation and crack growth toughness in ductile alloys. Metallurgical Transactions A 16A, pp. 236-248.

Said, G. and Tasgetiren, S., 2004. An express technique for the determination of static and dynamic fracture toughness of bcc metals and alloys, Mechanics of Materials, 36, 1129-1142. 
Sehitoglu, H, Sun, W., 1989. The significance of crack closure under high temperature fatigue crack growth with hold periods. Engineering Fracture Mechanics 33, 371388.

Sehitoglu, H, Sun, W., 1991. Modelling of plane strain fatigue crack closure. ASME Journal of Engineering Materials and Technology 113, 31-40.

Sung, J.C., Liou, J.Y., 1993. Transient crack growth in a viscoplastc solid. Engineering Fracture Mechanics 46, 399-411.

Tong, J., Dalby, S., Byrne, J., Henderson, M.B., Hardy, M.C., 2001. Creep, fatigue and oxidation in crack growth in advanced nickel base superalloys. International Journal of Fatigue 23, 897-902.

Tong, J., Dalby, S., Byrne, J., 2005. Crack growth in a new nickel-based superalloy at elevated temperature, part III - characterisation. Journal of Materials Science, 40, 1237-1243.

Tvergaard, V., 2004. On fatigue crack growth in ductile materials by crack-tip blunting. Journal of the Mechanics and Physics of Solids 52, 2149-2166.

Wilson, R., Palazotto, A., 1986. Viscoplastic fatigue in a superalloy at elevated temperatures. Fracture Mechanics: Seventeenth Volume, ASTM STP 905, 265-275.

Yaguchi, M., Takahashi, Y., 2005. Ratchetting of viscoplastic material with cyclic softening, part I: experiments on modified 9Cr-1Mo steel. International Journal of Plasticity 21, 43-65.

Yatomi, M., Nikbin, K.M., O’Dowd, N.P., 2003. Creep crack growth prediction using damage based approach. International Journal of Pressure Vessels and Piping 80, 573-583.

Zhan, Z.L., Tong J., 2007a. A study of cyclic plasticity and viscoplasticity in a new nickel-based superalloy using unified constitutive equations. Part I: evaluation and determination of material parameters. Mechanics of Materials, 39, 64-72.

Zhan, Z.L., Tong J., 2007b. A study of cyclic plasticity and viscoplasticity in a new nickel-based superalloy using unified constitutive equations. Part II: simulation of cyclic stress relaxation. Mechanics of Materials, 39, 73-80.

Zhao, L.G., O’Dowd, N.P., Busso, E.P., 2006. A coupled kinetic-constitutive approach to the study of high temperature crack initiation in single crystal nickel-base superalloys. Journal of the Mechanics and Physics of Solids 54, 288-309.

Zhao, L.G., Tong, J., Byrne, J., 2001. Finite element simulation of creep crack growth in a nickel base superalloy. Engineering Fracture Mechanics 68, 1157-1170. 
Zhao, L.G., Tong, J., Byrne, J., 2004. The evolution of the stress-strain fields near a fatigue crack tip and plasticity-induced crack closure revisited. Fatigue and Fracture of Engineering Materials and Structures 27, 19-29. 


\section{Figure Captions}

Fig.1a Comparison of UMAT solution and experimental data for the first cycle of a strain-controlled cyclic test with strain rate $d \varepsilon / d t=0.05 \% / \mathrm{s}$ and strain range $\Delta \varepsilon$ $=2 \%$.

Fig.1b Comparison of UMAT solution and experimental data for the first cycle of a strain-controlled cyclic test with a superimposed 100-second dwell period at both maximum and minimum loads.

Fig.2 (a) Finite element mesh for a CT specimen geometry and (b) the refined mesh for crack growth area $(\Delta=12.7 \mu \mathrm{m})$.

Fig.3a The evolution of stress-strain loops over 30 cycles at a Gauss integration point just ahead of the crack tip $\left(\mathrm{r}=3.8 \mu \mathrm{m}, \theta \approx 45^{\circ}\right)$ for load ratios $\mathrm{R}=-1,0$ and 0.5 , $P_{\max }=7 \mathrm{kN}$.

Fig.3b The accumulated maximum strain against the number of cycles for selected load ratios. The numbers in the brackets indicate the local stress ratios close to the crack tip $\left(r=3.8 \mu \mathrm{m}, \theta \approx 45^{\circ}\right)$ at the 30 th cycle.

Fig.4 The evolution of stress-strain loops over 30 cycles at a Gauss integration point just ahead of the crack tip $\left(\mathrm{r}=3.8 \mu \mathrm{m}, \theta \approx 45^{\circ}\right)$ for load ratios $\mathrm{R}=0.3$ and 0 with a constant load range $\Delta \mathrm{P}=7 \mathrm{kN}$.

Fig.5a The evolution of stress-strain loops over 30 cycles for a Gauss integration point just ahead of the crack tip $\left(\mathrm{r}=3.8 \mu \mathrm{m}, \theta \approx 45^{\circ}\right)$ at selected loading frequencies.

Fig.5b The accumulated maximum strain for a Gauss integration point just ahead of the crack tip $\left(\mathrm{r}=3.8 \mu \mathrm{m}, \theta \approx 45^{\circ}\right)$ against the number of cycles at selected loading frequencies. 
Fig.6a The evolution of stress-strain loops for a Gauss integration point just ahead of the crack tip $\left(\mathrm{r}=3.8 \mu \mathrm{m}, \theta \approx 45^{\circ}\right)$ for selected dwell periods.

Fig.6b The accumulated maximum strain for the Gauss integration point just ahead of the crack tip $(\mathrm{r}=3.8 \mu \mathrm{m})$ against the number cycles for selected dwell periods.

Fig.7a The strain and strain rate near a crack tip $\left(\mathrm{r}=3.8 \mu \mathrm{m}, \theta \approx 45^{\circ}\right)$ for monotonic loading, $P_{\max }=7 \mathrm{kN}$.

Fig. $7 \mathrm{~b}$ The stress and stress rate near a crack tip $\left(\mathrm{r}=3.8 \mu \mathrm{m}, \theta \approx 45^{\circ}\right)$ for monotonic loading, $P_{\max }=7 \mathrm{kN}$

Fig.7c The stress relaxation behaviour near the crack tip $\left(\mathrm{r}=3.8 \mu \mathrm{m}, \theta \approx 45^{\circ}\right)$ during hold periods at the maximum load, results from six cycles. Remote loading mode: load control.

Fig.7d The creep deformation behaviour near the crack tip $\left(r=3.8 \mu \mathrm{m}, \theta \approx 45^{\circ}\right)$ during hold periods at the maximum load, results from six cycles. Remote loading mode: load control.

Fig.8a The evolution of stress-strain loops at an integration point $\mathrm{O}$ ahead of a growing crack. The distances to the growing crack tip are: $\mathrm{AO}=29.2 \mu \mathrm{m}, \mathrm{BO}=16.5$ $\mu \mathrm{m}, \mathrm{CO}=3.8 \mu \mathrm{m}$.

Fig.8b The evolution of stress and strain ratios for a growing crack. The numbers in the brackets indicate the local stress ratios.

Fig.9a The evolution of stress-strain loops at a monitored element ahead of a growing crack $\left(l_{0}=0.1 \mathrm{~mm}\right)$ for two different loading frequencies. Results for 4 cycles are presented after the crack grows into the monitored element and the crack is assumed stationary momentarily. 
Fig.9b The accumulated strain against the number of cycles for a growing crack at two loading frequencies. The strain accumulation was calculated for the growth over a distance $l_{0}\left(l_{0}=0.1 \mathrm{~mm}\right)$.

Fig.10a The evolution of stress-strain loops at a monitored element ahead of a growing crack $\left(l_{0}=0.1 \mathrm{~mm}\right)$ for two different loading frequencies. Results for 4 cycles are presented after the crack grows into the monitored element and the crack is assumed stationary momentarily.

Fig.10b The accumulated strain against the number of cycles for a growing crack for two dwell periods. The strain accumulation was calculated for the growth over a distance $l_{0}\left(l_{0}=0.1 \mathrm{~mm}\right)$.

Fig.11 Crack growth rates against $\Delta \mathrm{K}$ for a triangular waveform with frequency $f=$ $0.25 \mathrm{~Hz}$ and load ratio $R=0.1$ at room temperature and $650^{\circ} \mathrm{C}$; comparison of model prediction and experimental results.

Fig.12 The effects of loading frequency on crack growth rate for a triangular waveform with $\Delta K=40 \mathrm{MPa} \sqrt{\mathrm{m}}$ and load ratio $R=0.1$ at $650^{\circ} \mathrm{C}$; comparison of model prediction and experimental results

Fig.13 The effects of dwell periods on crack growth rate for a trapezoidal loading waveform with $\Delta K=40 \mathrm{MPa} \sqrt{\mathrm{m}}$ and load ratio $R=0.1$ at $650^{\circ} \mathrm{C}$; comparison of model prediction and experimental results. 


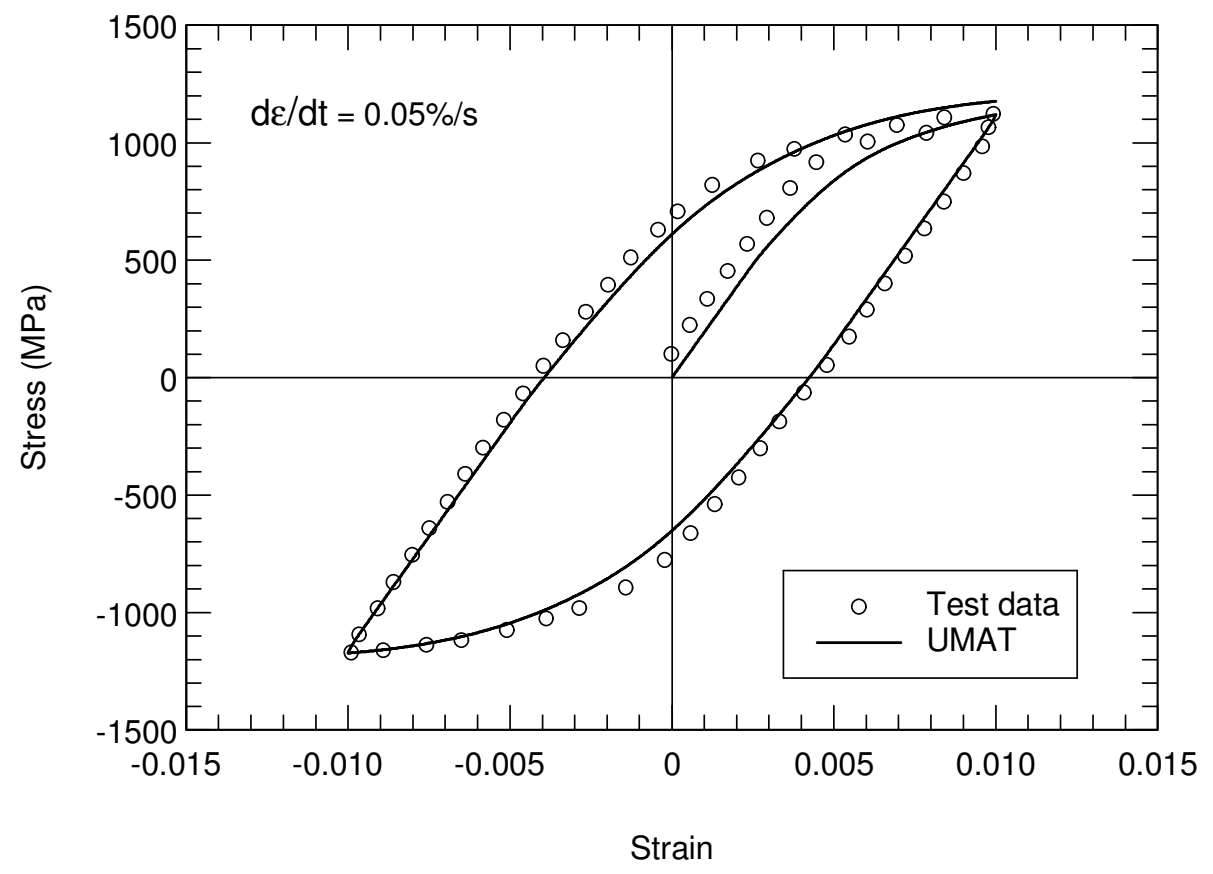

Fig.1a Comparison of UMAT solution and experimental data for the first cycle of a strain-controlled cyclic test with strain rate $d \varepsilon / d t=0.05 \% / \mathrm{s}$ and strain range $\Delta \varepsilon=2 \%$. 


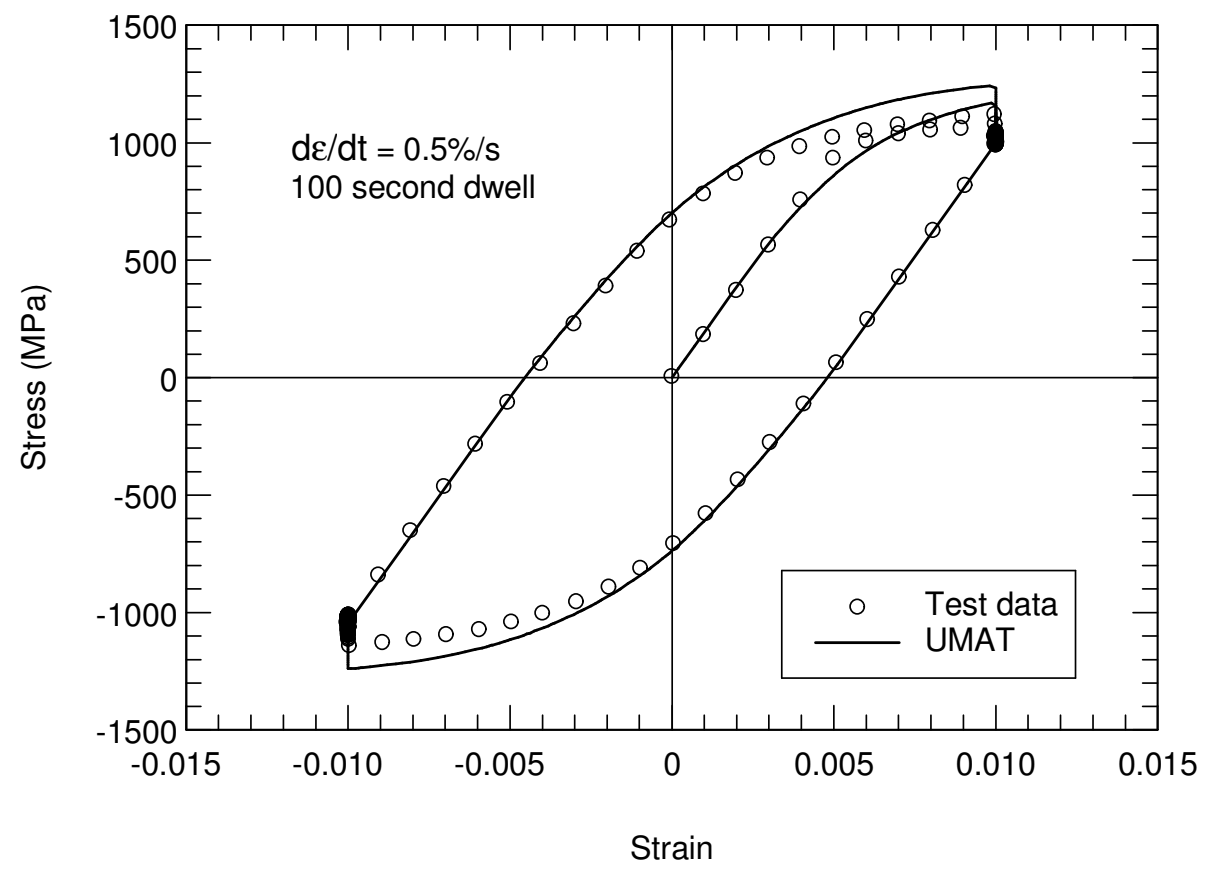

Fig.1b Comparison of UMAT solution and experimental data for the first cycle of a strain-controlled cyclic test with a superimposed 100 -second dwell period at both maximum and minimum loads. 
(a)
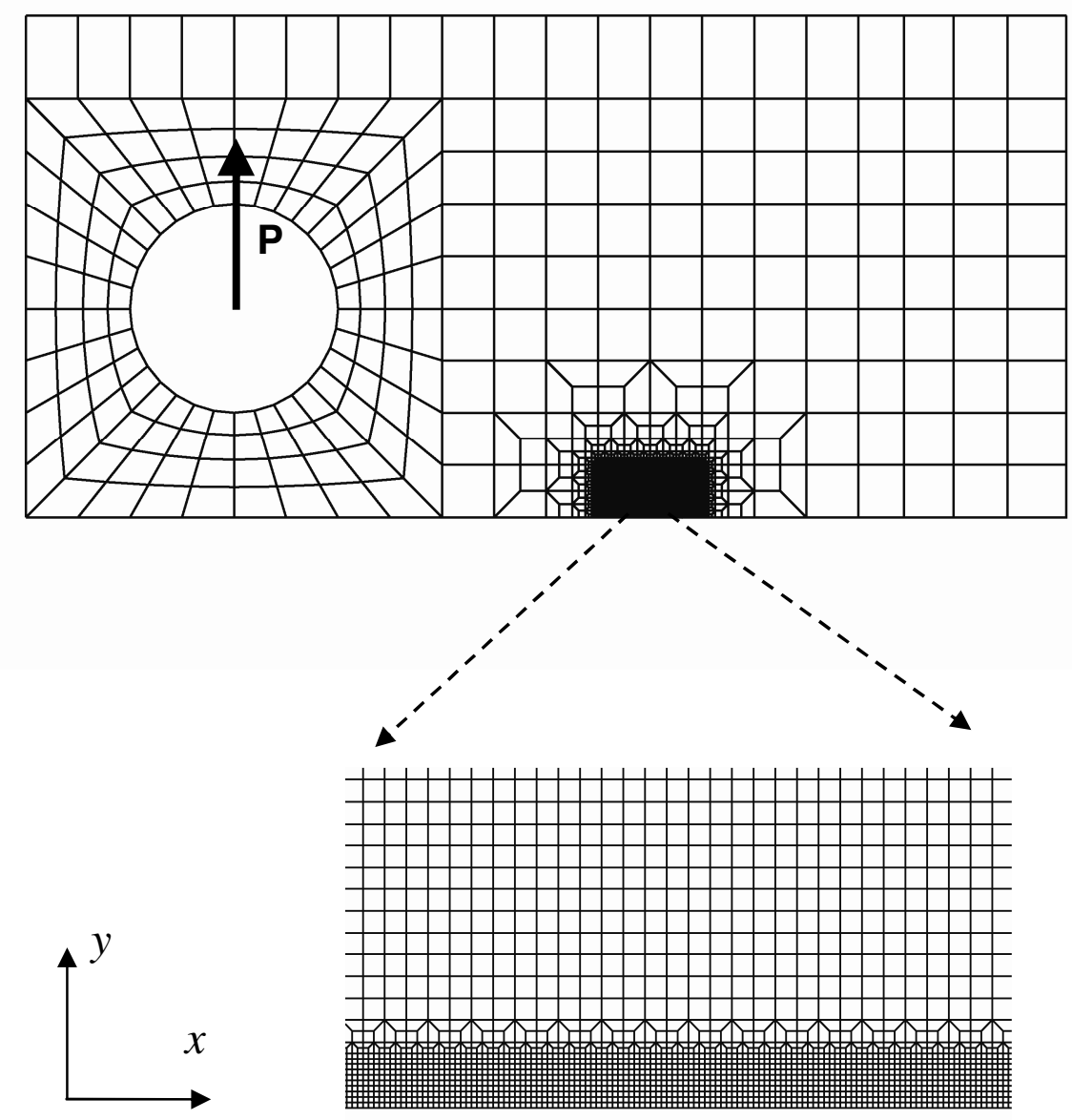

(b)

Fig.2 (a) Finite element mesh for a CT specimen geometry and (b) the refined mesh for crack growth area $(\Delta=12.7 \mu \mathrm{m})$. 


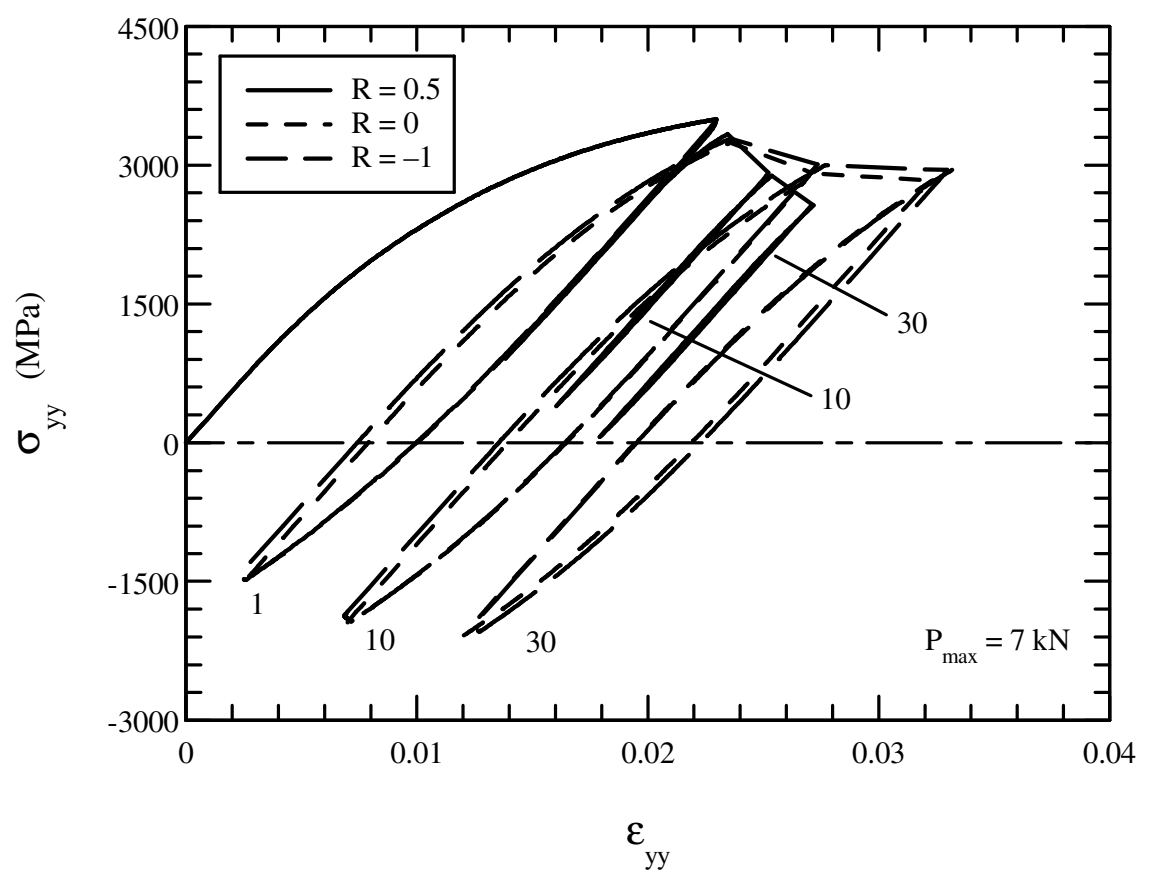

Fig.3a The evolution of stress-strain loops over 30 cycles at a Gauss integration point just ahead of the crack tip $\left(\mathrm{r}=3.8 \mu \mathrm{m}, \theta \approx 45^{\circ}\right)$ for load ratios $\mathrm{R}=-1,0$ and $0.5, P_{\max }=7$ $\mathrm{kN}$. 


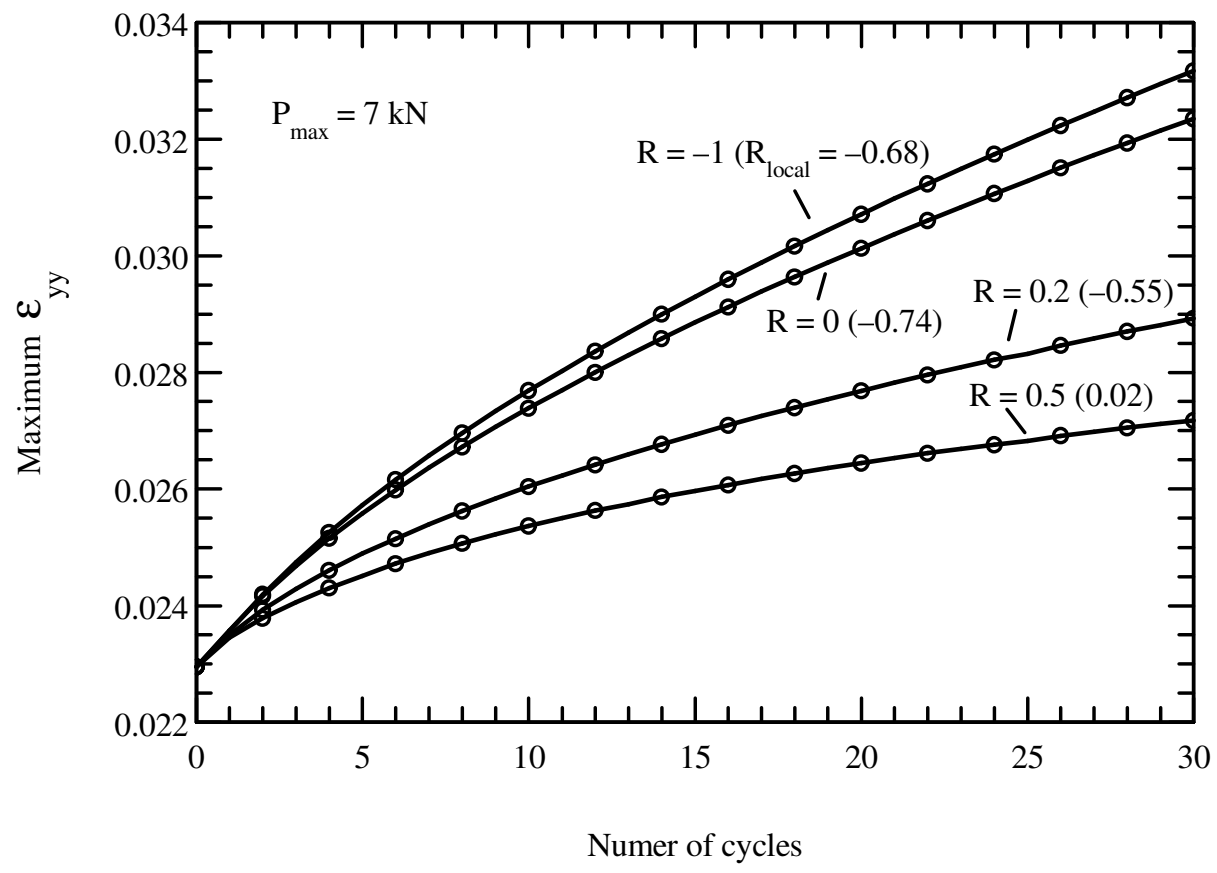

Fig.3b The accumulated maximum strain against the number of cycles for selected load ratios. The numbers in the brackets indicate the local stress ratios close to the crack tip ( $\mathrm{r}$ $=3.8 \mu \mathrm{m}, \theta \approx 45^{\circ}$ ) at the 30th cycle. 


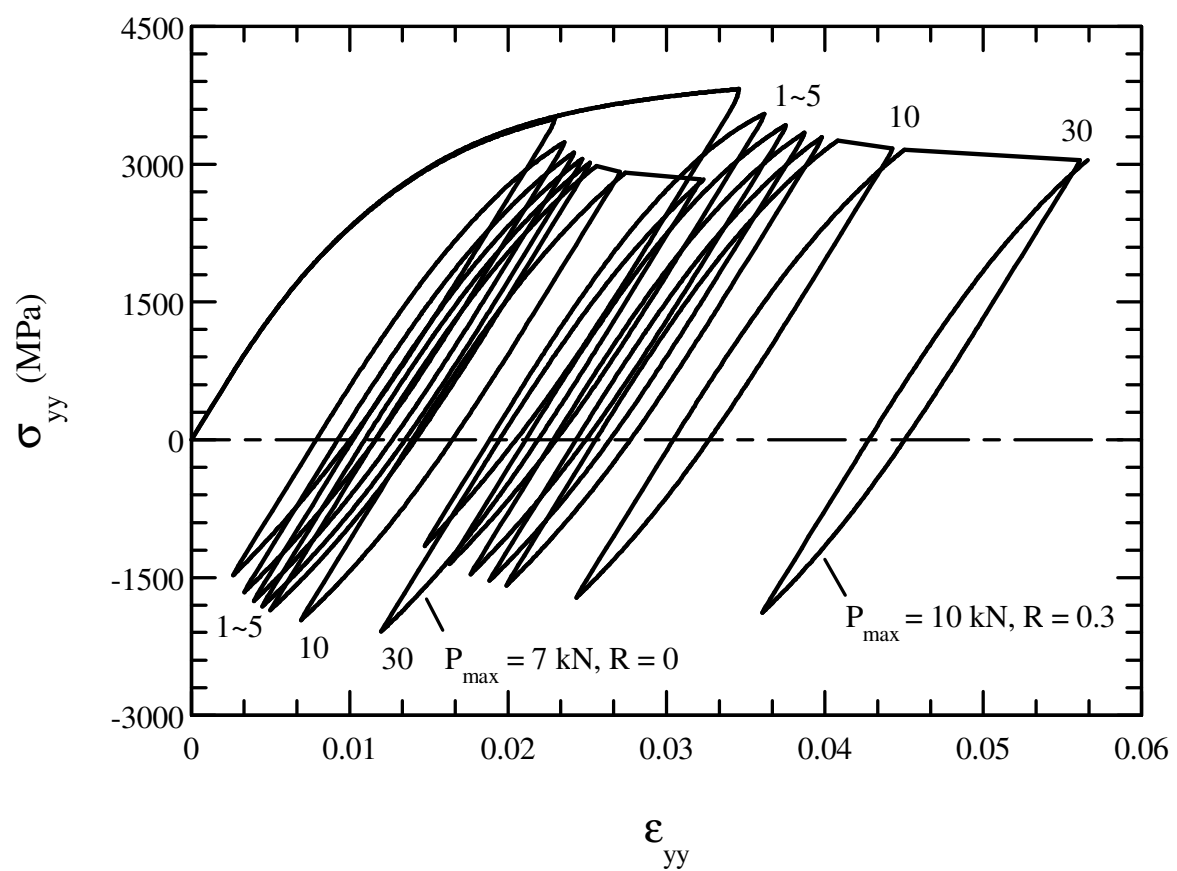

Fig.4 The evolution of stress-strain loops over 30 cycles at a Gauss integration point just ahead of the crack tip $\left(\mathrm{r}=3.8 \mu \mathrm{m}, \theta \approx 45^{\circ}\right)$ for load ratios $\mathrm{R}=0.3$ and 0 with a constant load range $\Delta \mathrm{P}=7 \mathrm{kN}$. 


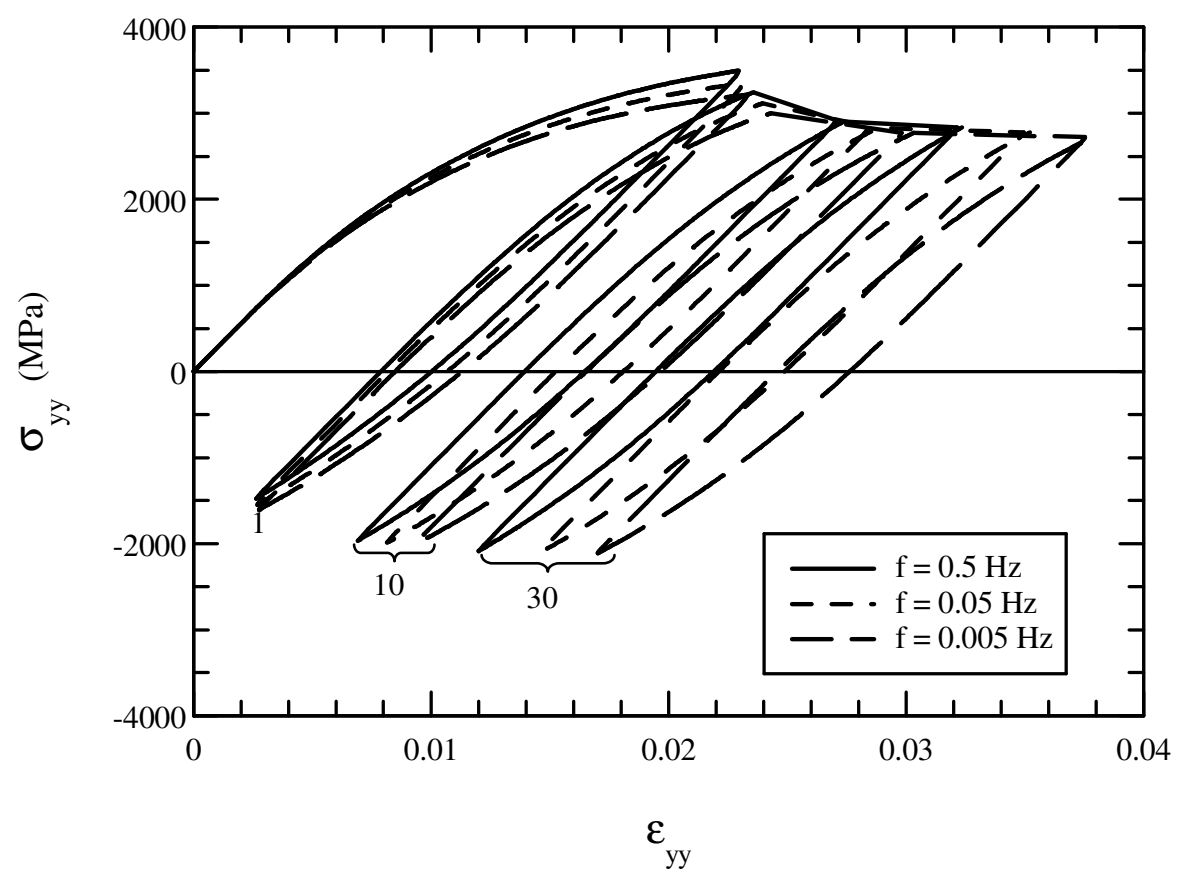

Fig.5a The evolution of stress-strain loops over 30 cycles for a Gauss integration point just ahead of the crack tip $\left(\mathrm{r}=3.8 \mu \mathrm{m}, \theta \approx 45^{\circ}\right)$ at selected loading frequencies. 


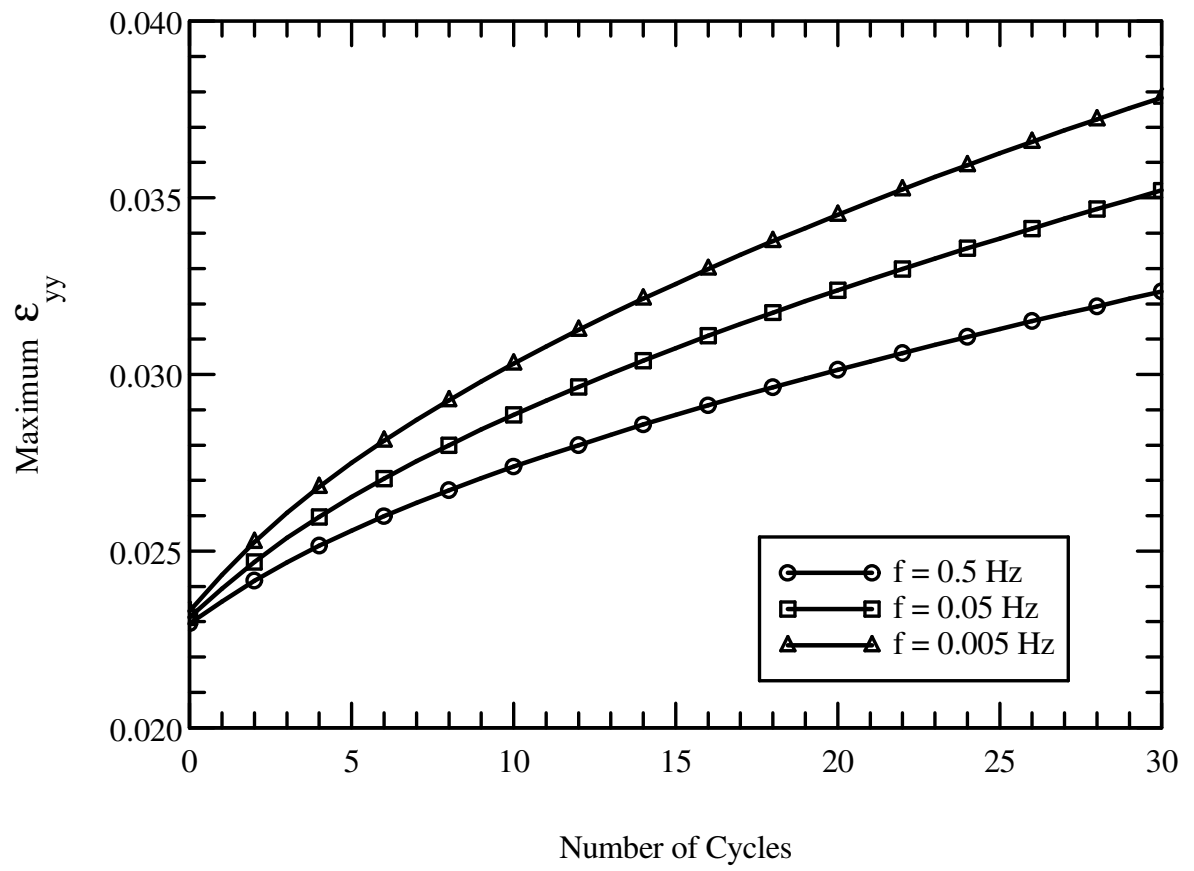

Fig.5b The accumulated maximum strain for a Gauss integration point just ahead of the crack tip $\left(\mathrm{r}=3.8 \mu \mathrm{m}, \theta \approx 45^{\circ}\right)$ against the number of cycles at selected loading frequencies. 


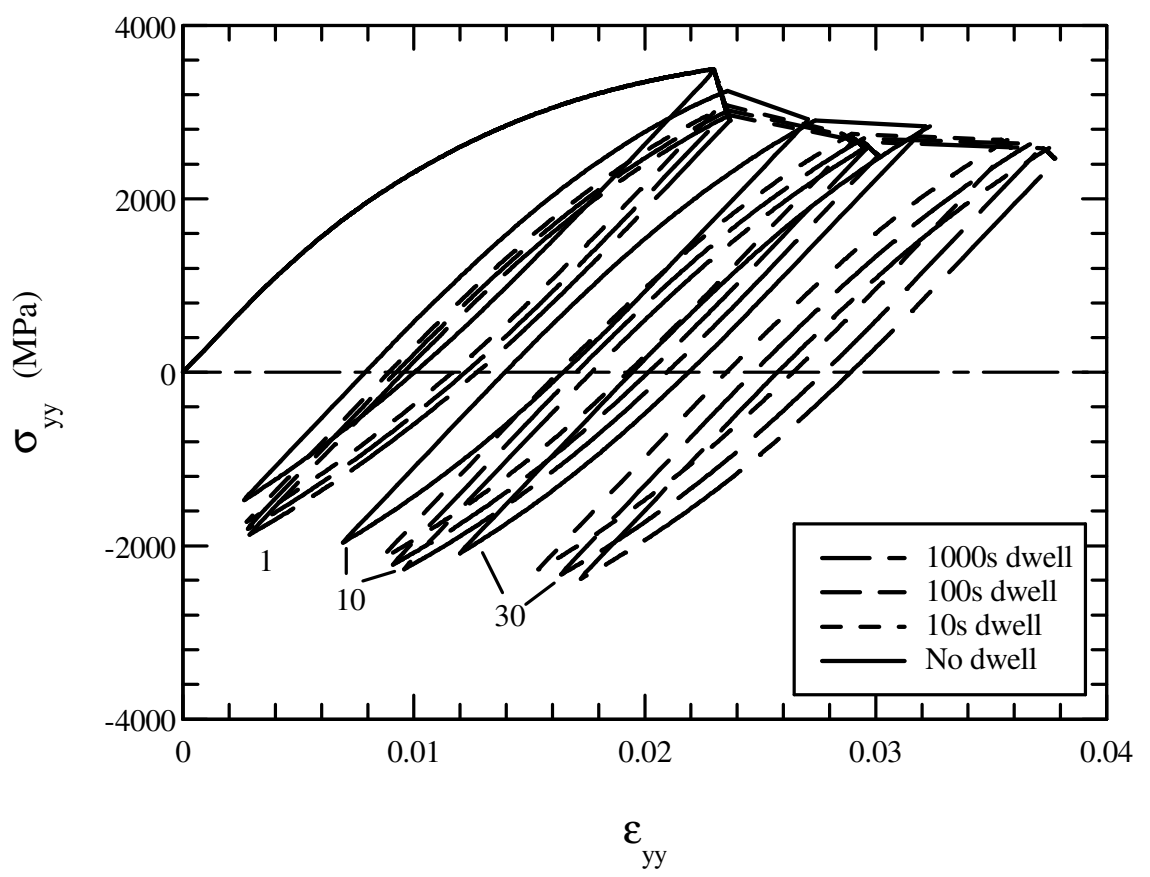

Fig.6a The evolution of stress-strain loops for a Gauss integration point just ahead of the crack tip $\left(r=3.8 \mu \mathrm{m}, \theta \approx 45^{\circ}\right)$ for selected dwell periods. 


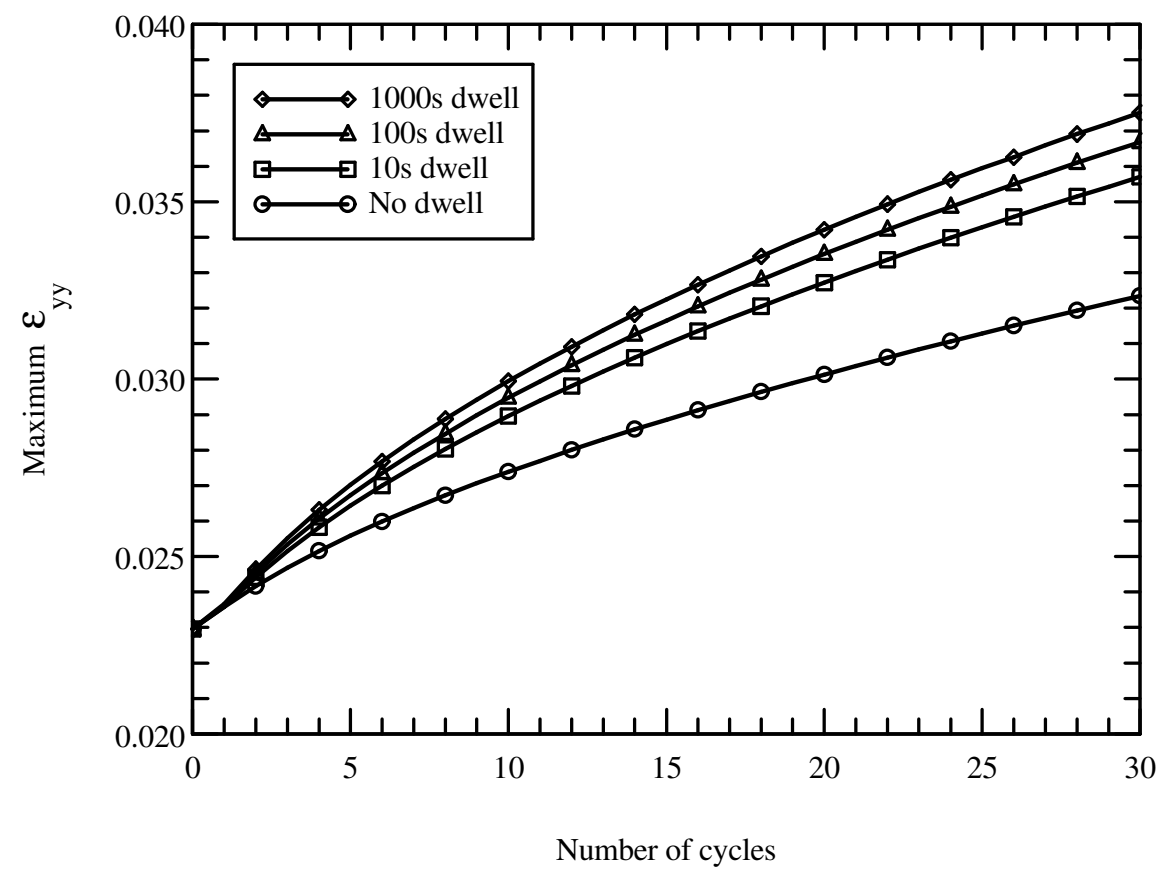

Fig.6b The accumulated maximum strain for the Gauss integration point just ahead of the crack tip $(\mathrm{r}=3.8 \mu \mathrm{m})$ against the number cycles for selected dwell periods. 


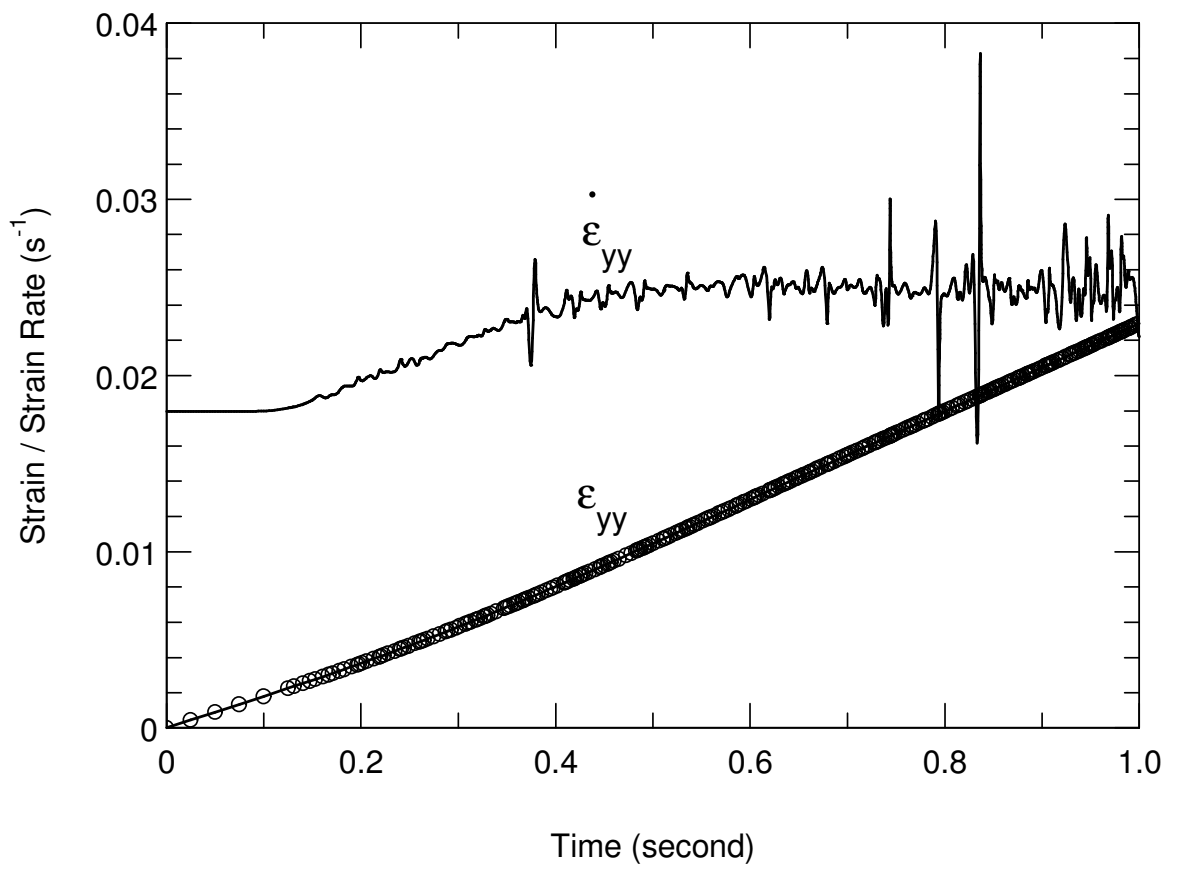

Fig. $7 \mathrm{a}$ The strain and strain rate near a crack tip $\left(\mathrm{r}=3.8 \mu \mathrm{m}, \theta \approx 45^{\circ}\right)$ for monotonic loading, $P_{\max }=7 \mathrm{kN}$. 


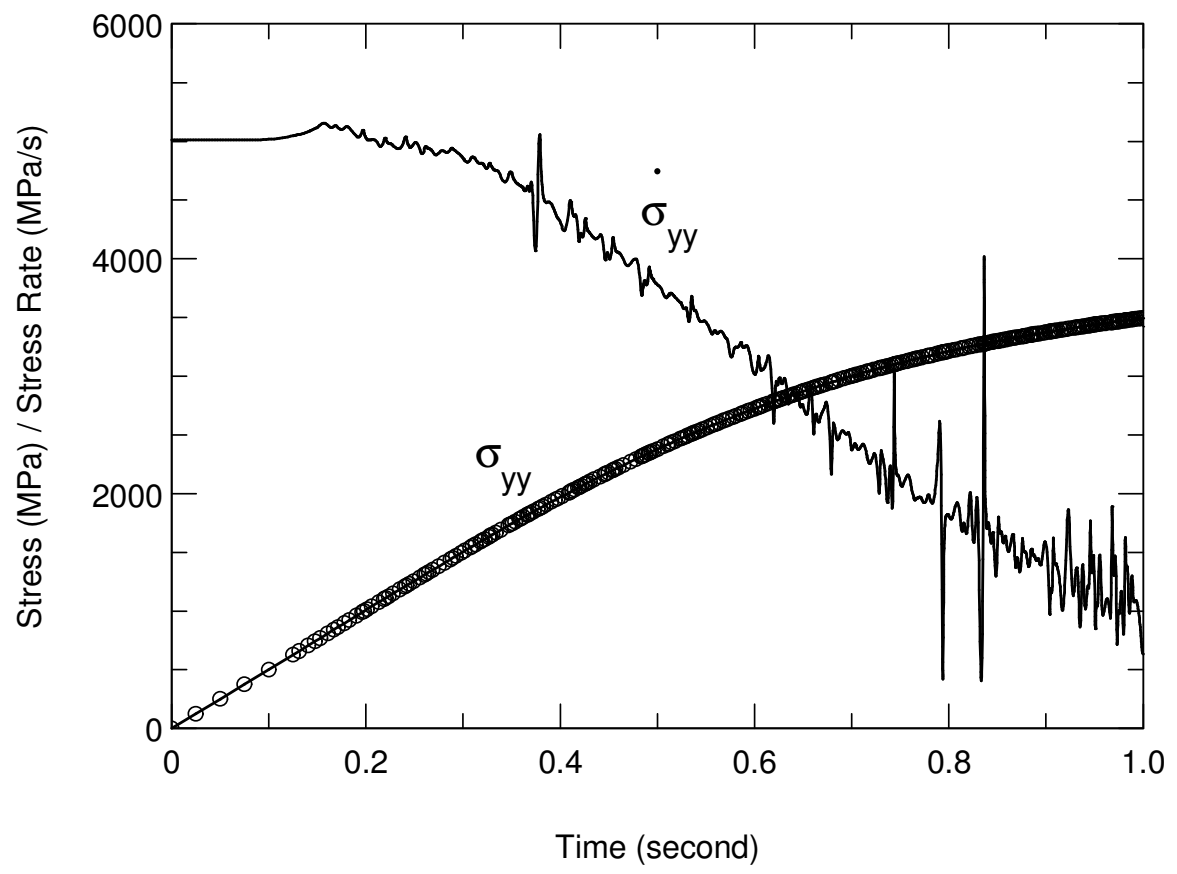

Fig. $7 \mathrm{~b}$ The stress and stress rate near a crack tip $\left(\mathrm{r}=3.8 \mu \mathrm{m}, \theta \approx 45^{\circ}\right)$ for monotonic loading, $P_{\max }=7 \mathrm{kN}$. 


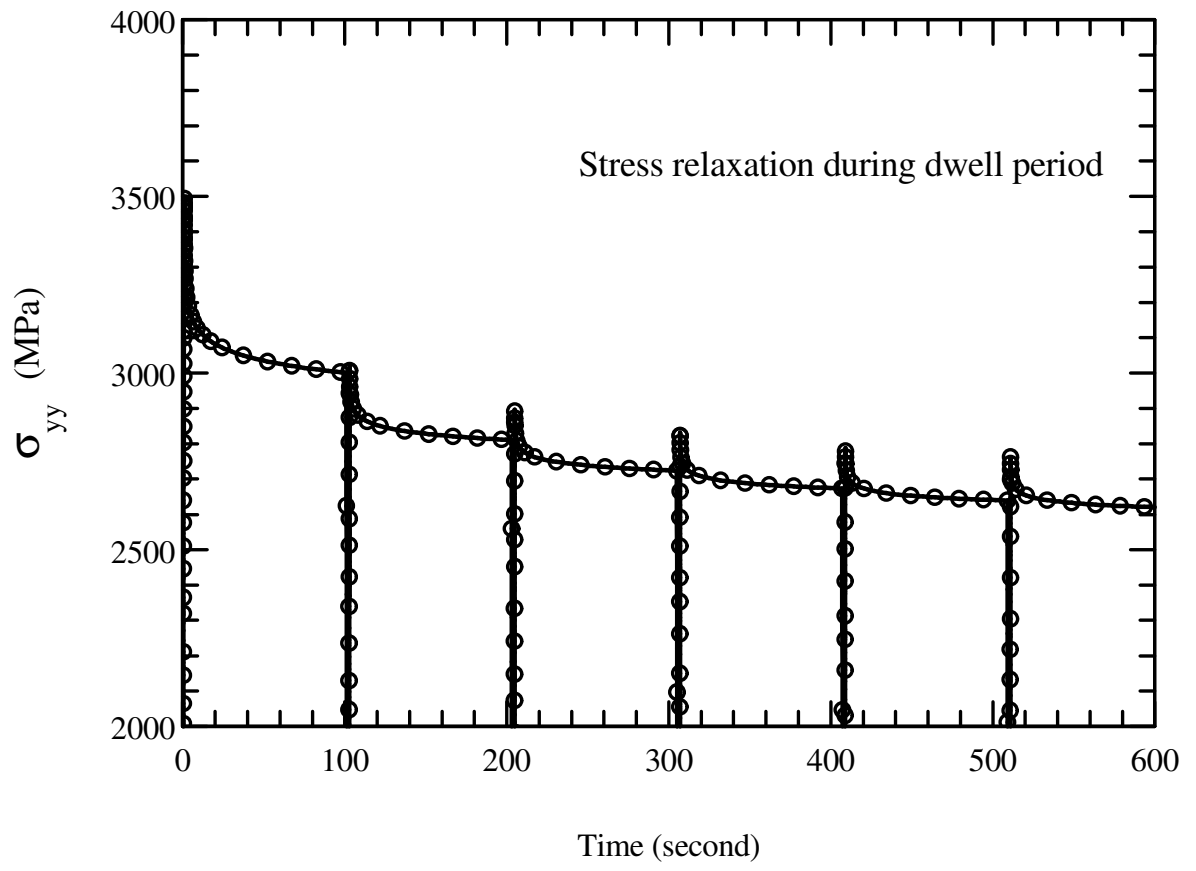

Fig.7c The stress relaxation behaviour near the crack tip $\left(\mathrm{r}=3.8 \mu \mathrm{m}, \theta \approx 45^{\circ}\right)$ during hold periods at the maximum load, results from six cycles. Remote loading mode: load control. 


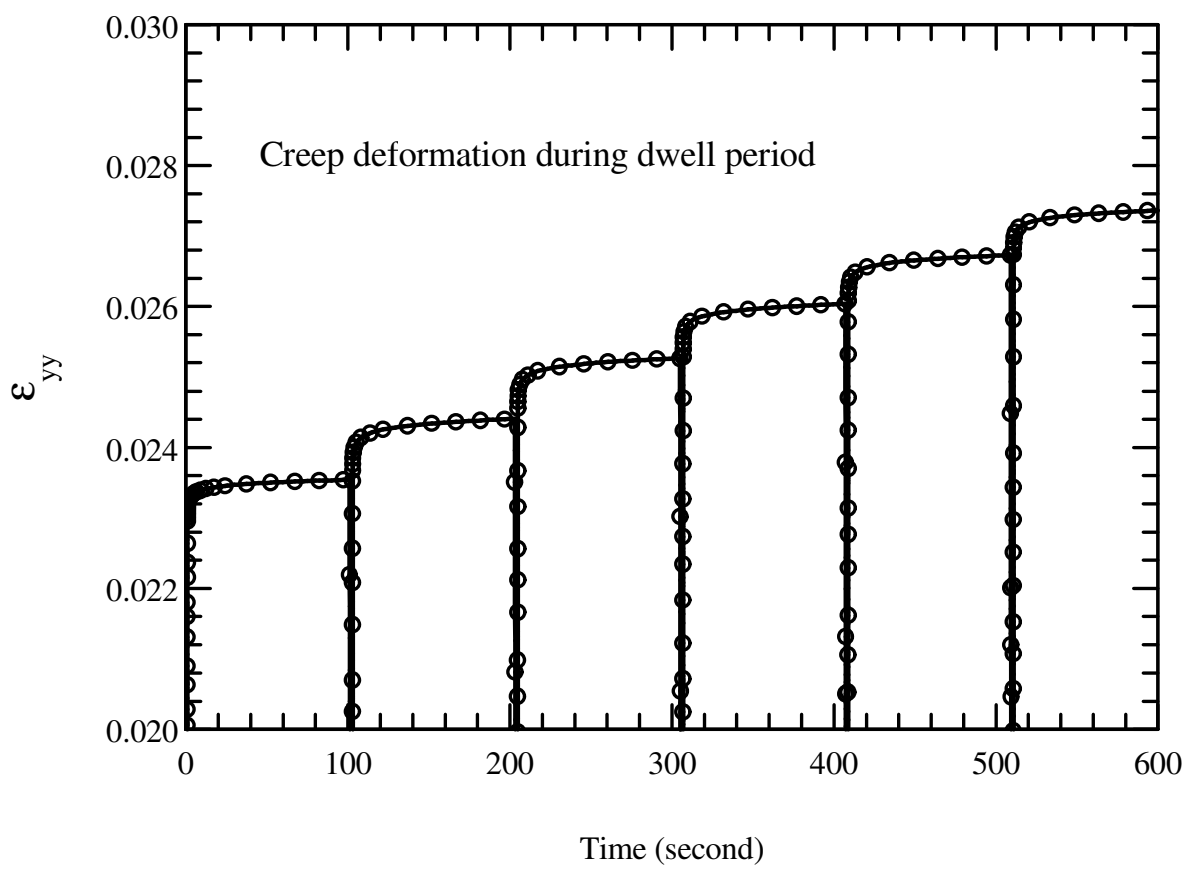

Fig. $7 \mathrm{~d}$ The creep deformation behaviour near the crack tip $\left(\mathrm{r}=3.8 \mu \mathrm{m}, \theta \approx 45^{\circ}\right)$ during hold periods at the maximum load, results from six cycles. Remote loading mode: load control. 


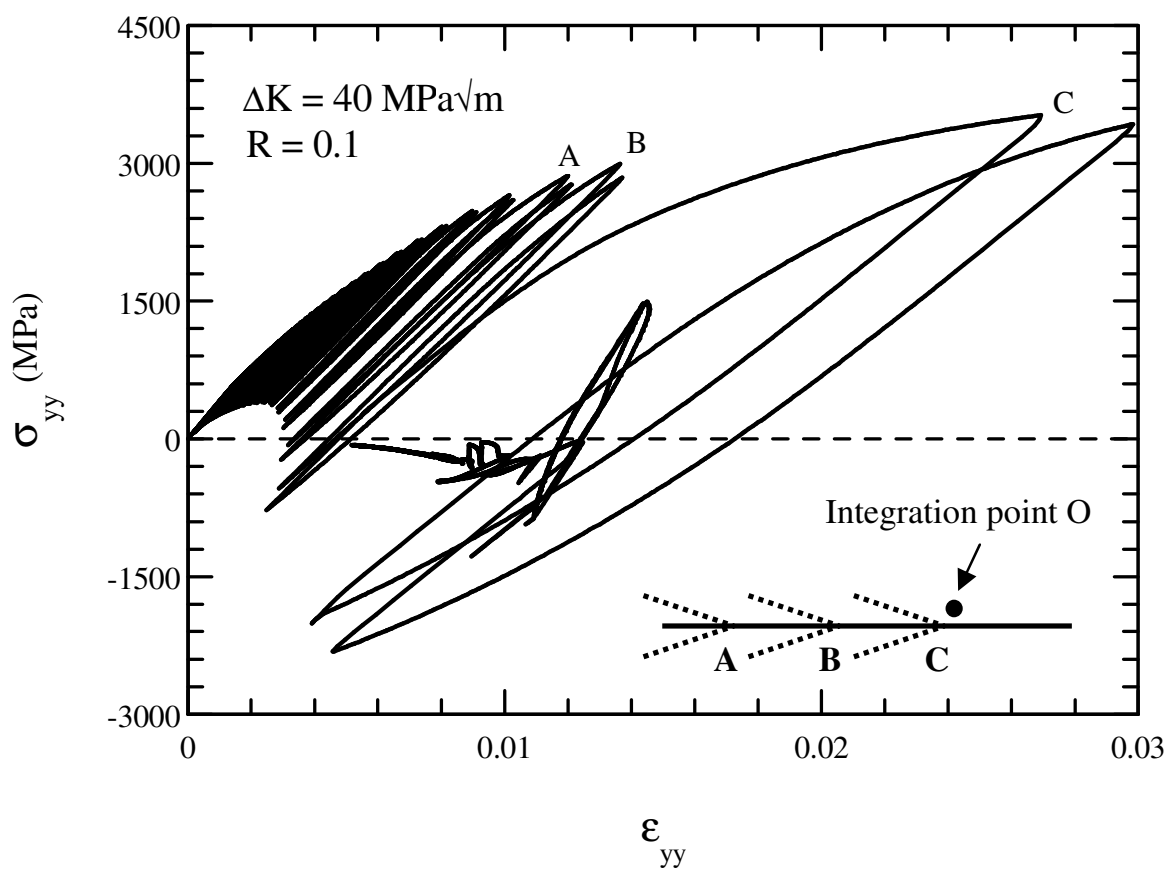

Fig.8a The evolution of stress-strain loops at an integration point $\mathrm{O}$ ahead of a growing crack. The distances to the growing crack tip are: $\mathrm{AO}=29.2 \mu \mathrm{m}, \mathrm{BO}=16.5 \mu \mathrm{m}, \mathrm{CO}=$ $3.8 \mu \mathrm{m}$. 


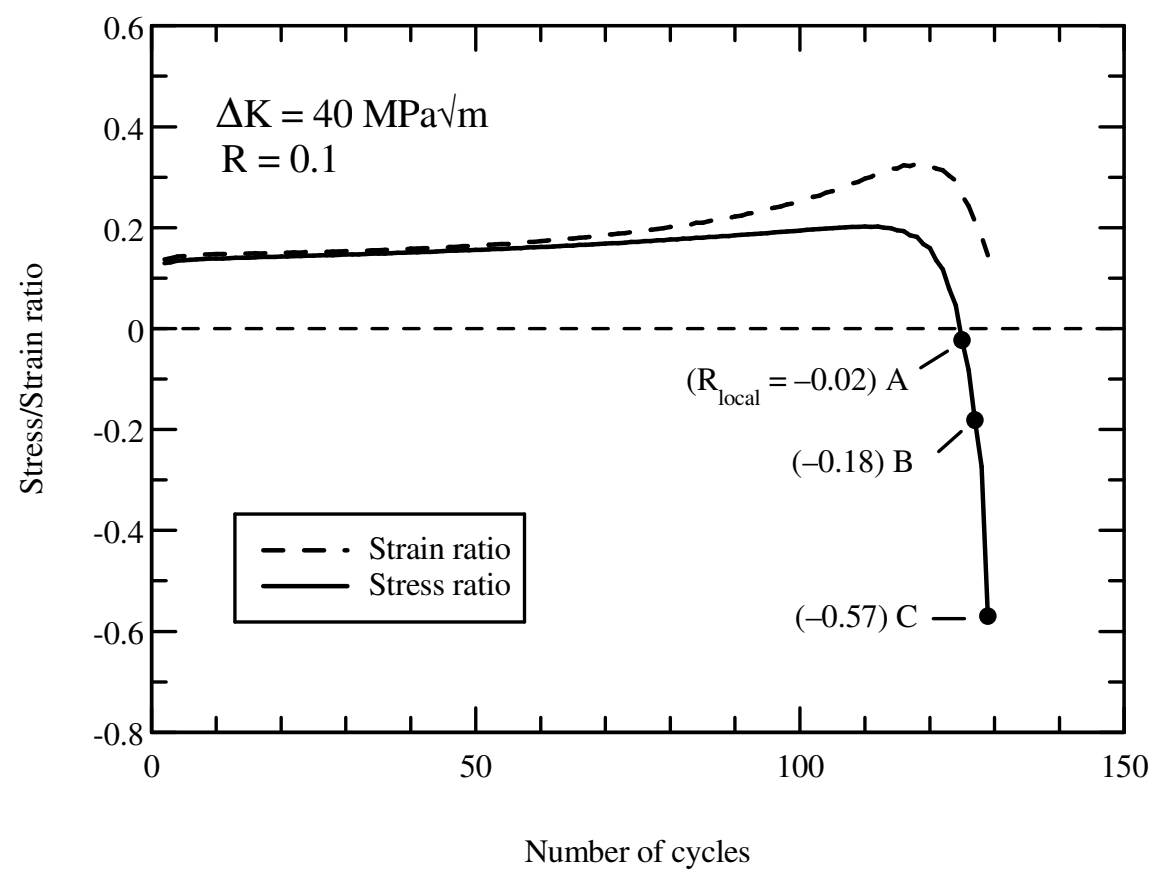

Fig.8b The evolution of stress and strain ratios for a growing crack. The numbers in the brackets indicate the local stress ratios. 


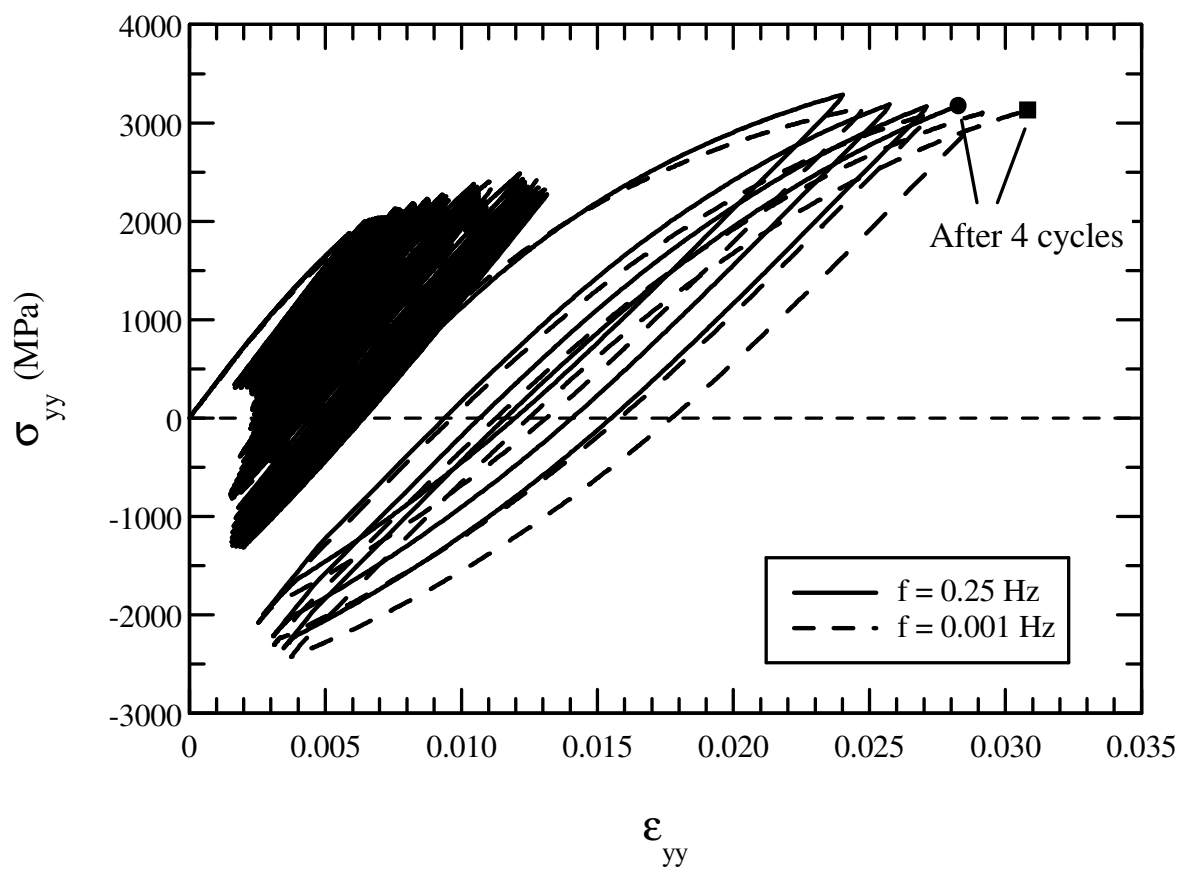

Fig.9a The evolution of stress-strain loops at a monitored element ahead of a growing crack $\left(l_{0}=0.1 \mathrm{~mm}\right)$ for two different loading frequencies. Results for 4 cycles are presented after the crack grows into the monitored element and the crack is assumed stationary momentarily. 


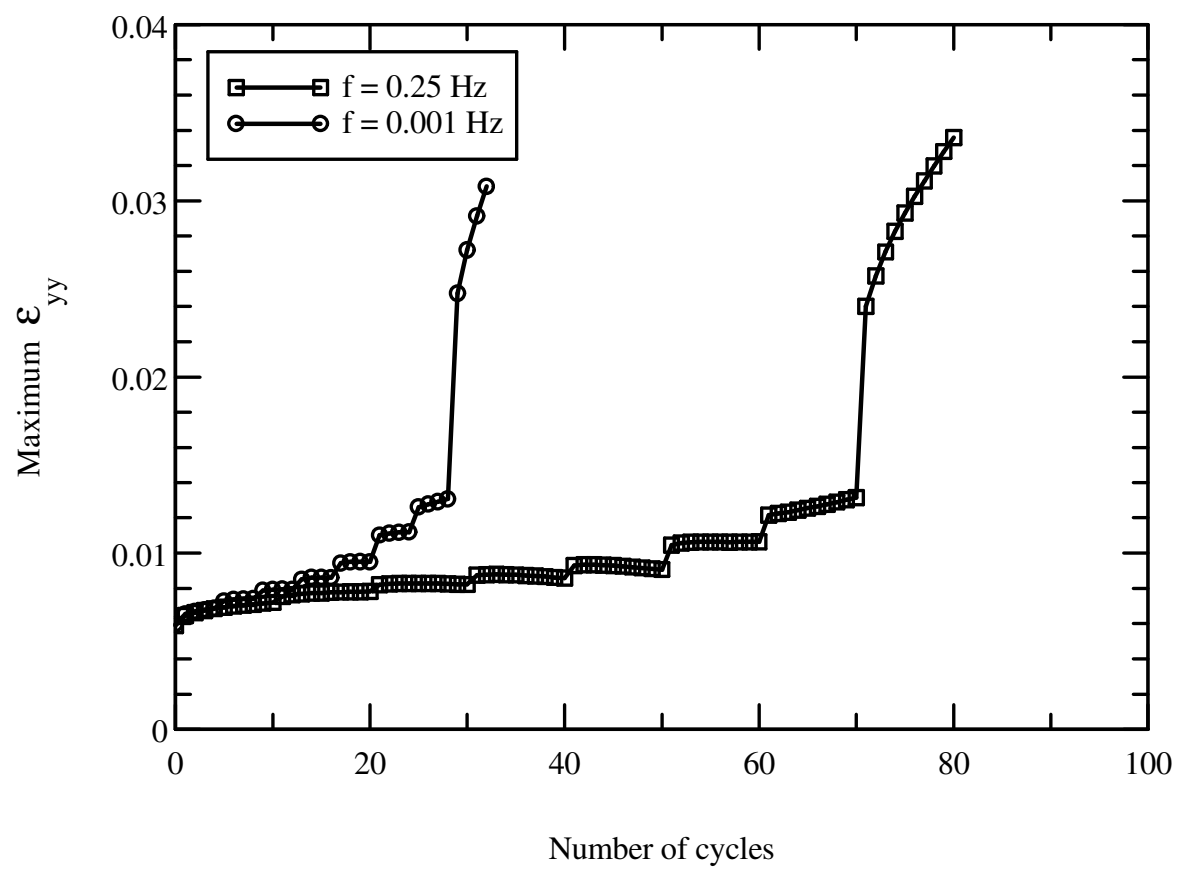

Fig.9b The accumulated strain against the number of cycles for a growing crack at two loading frequencies. The strain accumulation was calculated for the growth over a distance $l_{0}\left(l_{0}=0.1 \mathrm{~mm}\right)$. 


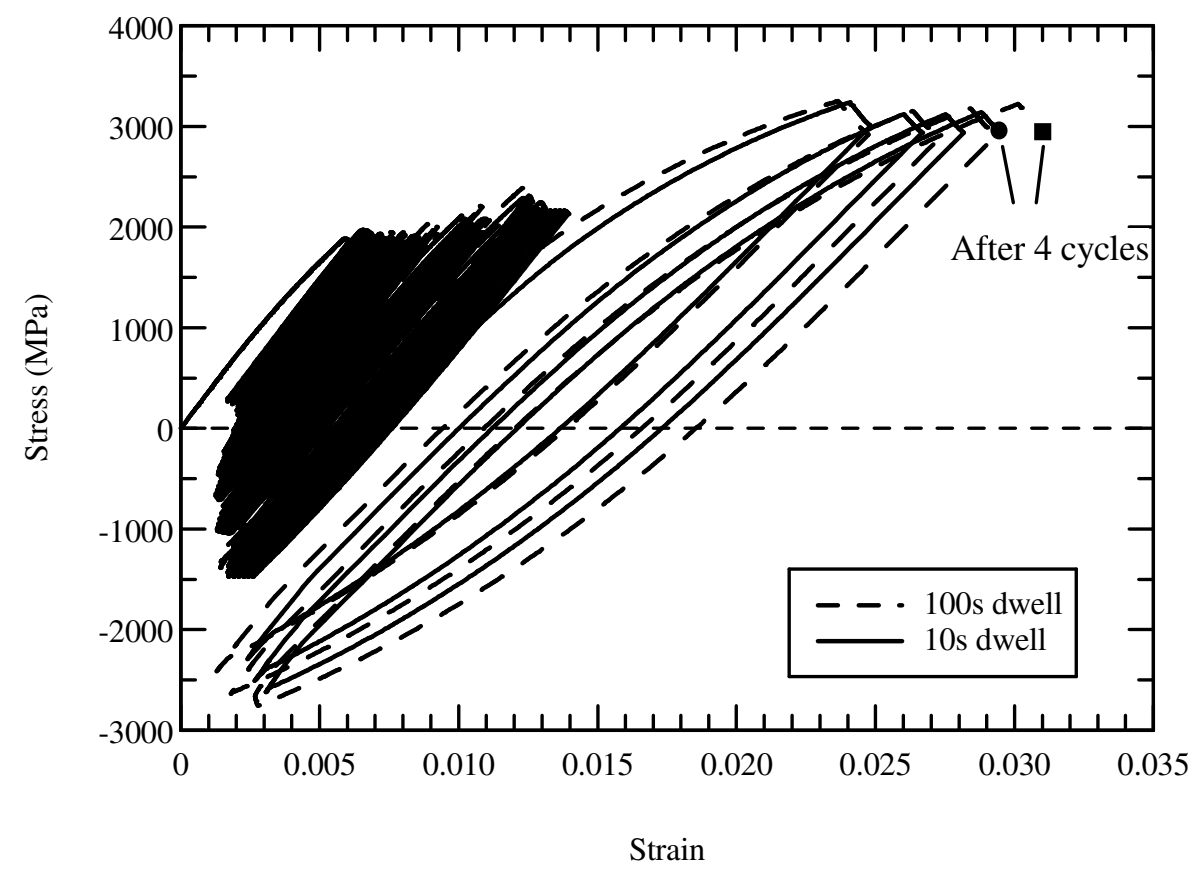

Fig.10a The evolution of stress-strain loops at a monitored element ahead of a growing crack $\left(l_{0}=0.1 \mathrm{~mm}\right)$ for two different loading frequencies. Results for 4 cycles are presented after the crack grows into the monitored element and the crack is assumed stationary momentarily. 


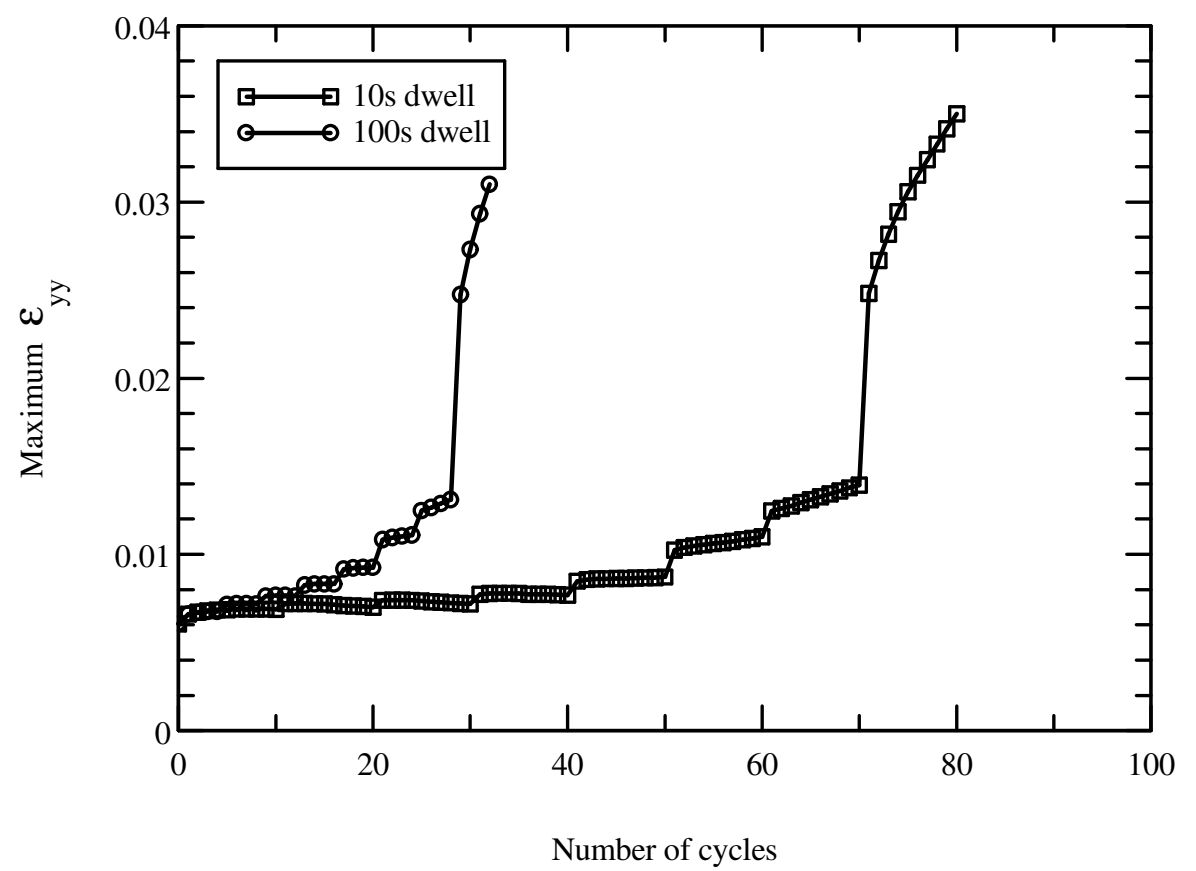

Fig.10b The accumulated strain against the number of cycles for a growing crack for two dwell periods. The strain accumulation was calculated for the growth over a distance $l_{0}$ $\left(l_{0}=0.1 \mathrm{~mm}\right)$. 


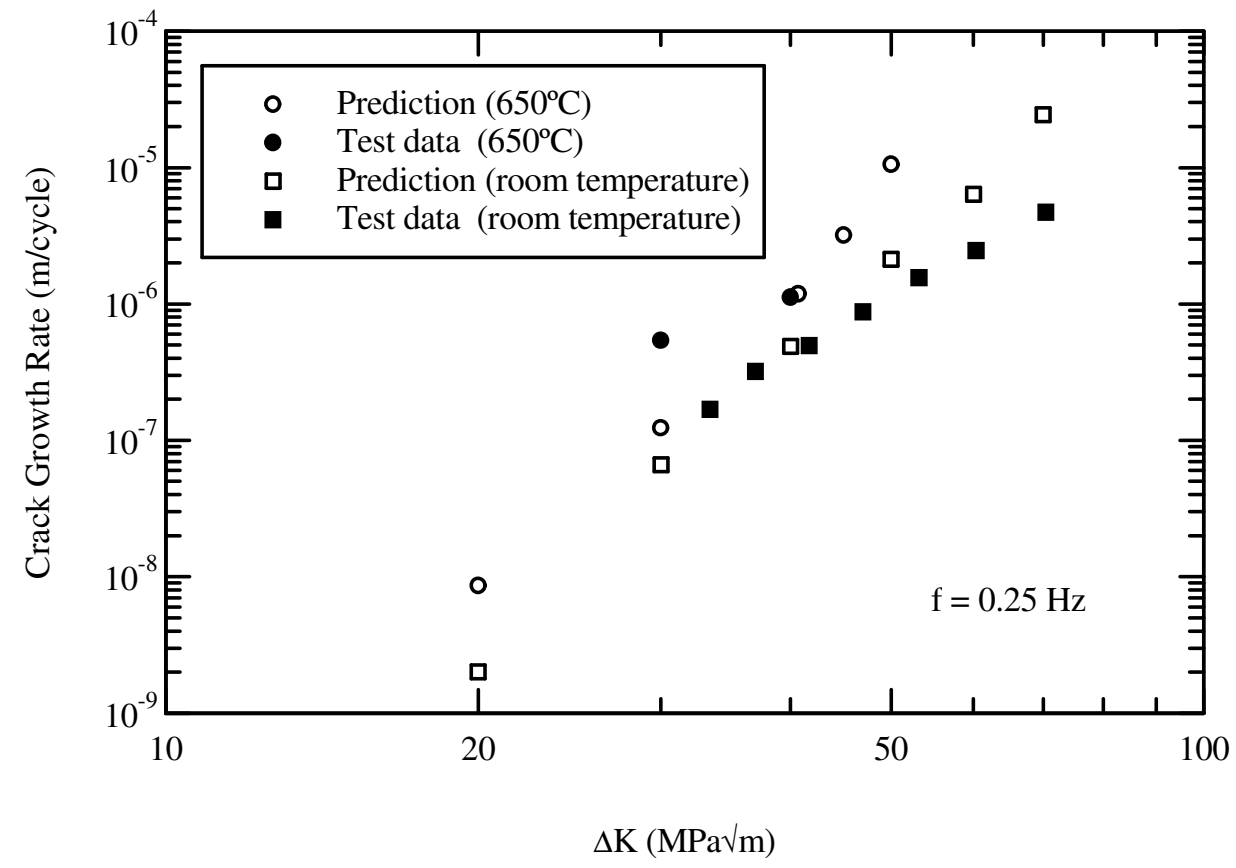

Fig. 11 Crack growth rates against $\Delta \mathrm{K}$ for a triangular waveform with frequency $f=0.25$ $\mathrm{Hz}$ and load ratio $R=0.1$ at room temperature and $650^{\circ} \mathrm{C}$; comparison of model prediction and experimental results. 


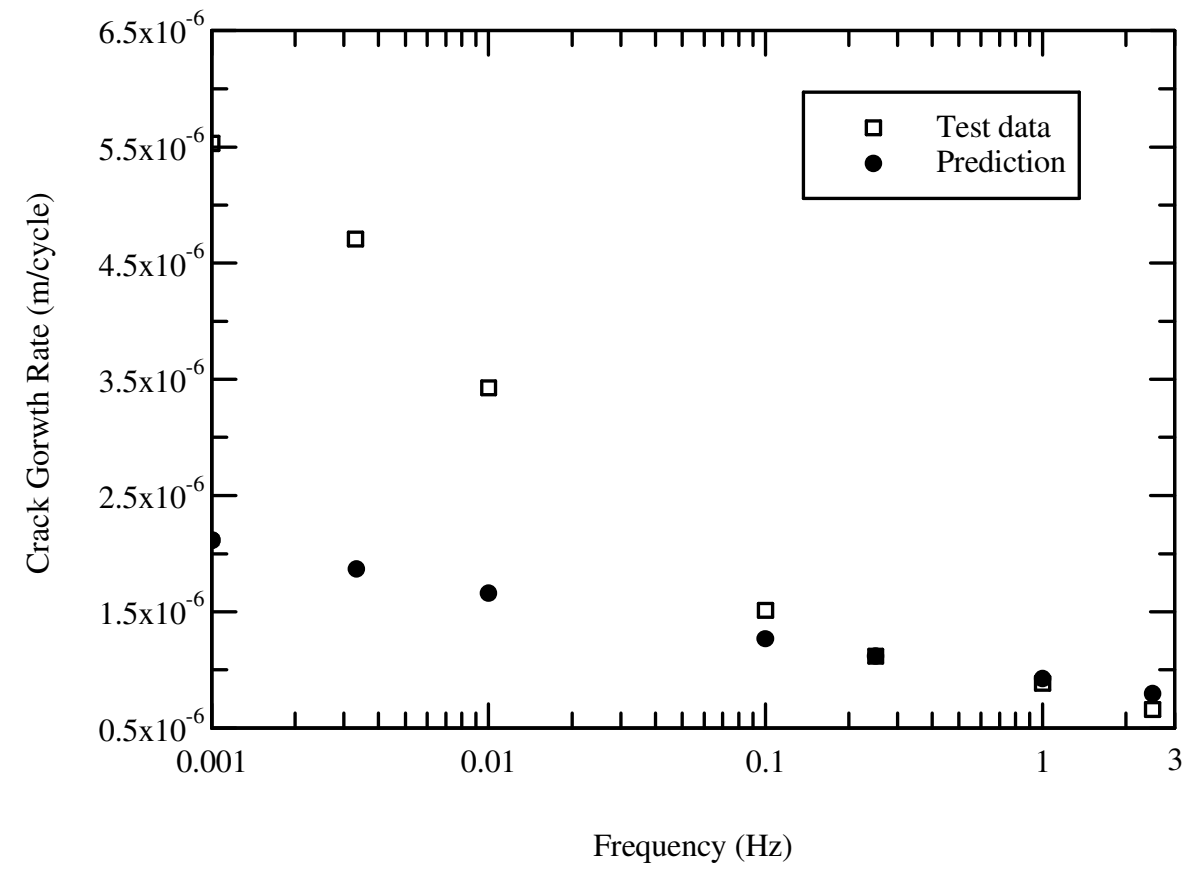

Fig. 12 The effects of loading frequency on crack growth rate for a triangular waveform with $\Delta K=40 \mathrm{MPa} \sqrt{\mathrm{m}}$ and load ratio $R=0.1$ at $650^{\circ} \mathrm{C}$; comparison of model prediction and experimental results. 


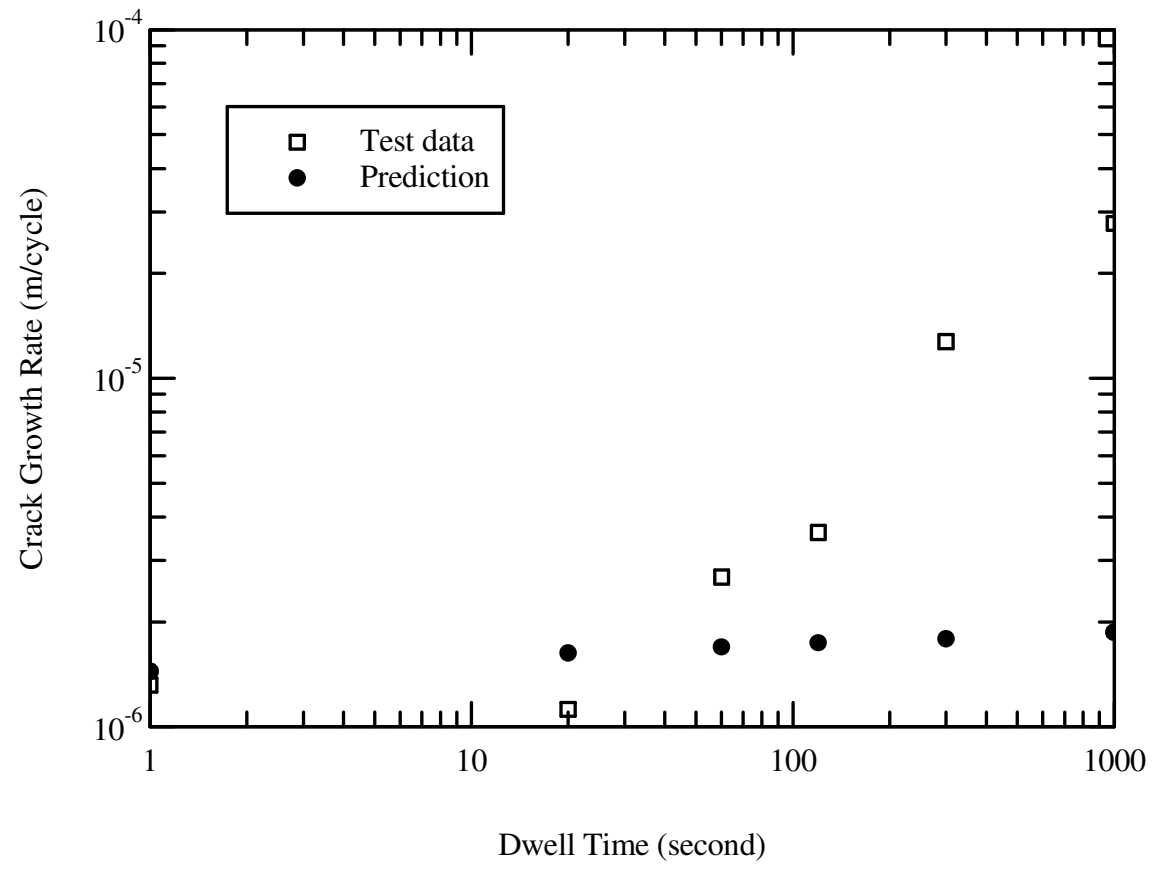

Fig.13 The effects of dwell periods on crack growth rate for a trapezoidal loading waveform with $\Delta K=40 \mathrm{MPa} \sqrt{\mathrm{m}}$ and load ratio $R=0.1$ at $650^{\circ} \mathrm{C}$; comparison of model prediction and experimental results. 
Table 1. Values of the material parameters for the viscoplastic constitutive material model.

\begin{tabular}{ll}
\hline Parameters & Optimised values \\
\hline$E(\mathrm{GPa})$ & 190 \\
\hline$v$ & 0.285 \\
\hline$b$ & 7.13 \\
\hline$Q(\mathrm{MPa})$ & 161.52 \\
\hline$a_{1}(\mathrm{MPa})$ & 361.57 \\
\hline$C_{1}$ & 391.61 \\
\hline$a_{2}(\mathrm{MPa})$ & 266.84 \\
\hline$C_{2}$ & 2578.69 \\
\hline$Z$ & 678.317 \\
\hline$n$ & 15.496 \\
\hline$k(\mathrm{MPa})$ & 144.26 \\
\hline
\end{tabular}

